$\underline{\text { Research Article }}$

\title{
How and why policy-practice gaps come about: a South African Universal Health Coverage context
}

Janet Michel ${ }^{1}$, Natsayi Chimbindi ${ }^{2}$, Nthabiseng Mohlakoana ${ }^{3}$, Marsha Orgill ${ }^{4}$, Till Bärnighausen ${ }^{5}$, Brigit Obrist ${ }^{6}$, Fabrizio Tediosi ${ }^{1}$, David Evans ${ }^{7}$, Di McIntryre ${ }^{8}$, Hans T Bressers ${ }^{9}$, Marcel Tanner ${ }^{1}$

1 Swiss Tropical and Public Health Institute (Swiss TPH), Basel, Switzerland, ${ }^{2}$ Africa Health Research Institute, South Africa, ${ }^{3}$ Department of Governance and Technology for Sustainability, University of Twente, Enschede, Netherlands, ${ }^{4}$ Health Policy and Systems Researcher, University of Cape Town, Cape Town, South Africa, 5 Professor Global Health, Harvard T. H. Chan School of Public Health, Boston, USA, 6 Professor Anthropology, University of Basel, Basel, Switzerland, 7 World Bank Health Economist, Geneva, Switzerland, ${ }^{8}$ Health Economics Unit, University of Cape Town, South Africa, ${ }^{9}$ Policy Studies and Environmental Policy, University of Twente, Enschede, Netherlands

Keywords: south africa, universal health coverage, global health

https://doi.org/10.29392/joghr.3.e2019069

\section{Journal of Global Health Reports}

Vol. 3, 2019

\section{Background}

South Africa, like many other countries is currently piloting National Health Insurance (NHI) reforms aimed at achieving Universal Health Coverage (UHC). Existing health policy implementation experience has demonstrated that new policies have sometimes generated unexpected and negative outcomes without necessarily explaining how these came about. Policies are not always implemented as envisioned, hence the importance of understanding the nature of policy implementation.

\section{Methods}

Qualitative data were collected during three phases: 2011-2012 (contextual mapping), 2013-2014 (phase 1) and 2015 (phase 2). In-depth face-to-face interviews were held with key informants $(n=71)$ using a theory of change interview guide, adapted for each phase. Key informants ranged from provincial actors (policy makers) district, subdistrict and primary health care (PHC) facility actors (policy implementers). All interviews were audio-recorded and transcribed. An iterative, inductive and deductive data analysis approach was utilized. Transcripts were coded with the aid of MAXQDA2018 (VERBI software $\mathrm{GmbH}$, Germany).

\section{Results}

Five groups of factors bringing about policy-practice gaps were identified. (i) Primary factors stemming from a direct lack of a critical component for policy implementation, tangible or intangible (resources, information, motivation, power); (ii) secondary factors stemming from a lack of efficient processes or systems (budget processes, limited financial delegations, top down directives, communication channels, supply chain processes, ineffective supervision and performance management systems); (iii) tertiary factors stemming from human factors (perception and cognition) and calculated human responses to a lack of primary, secondary and or extraneous factors, as coping mechanisms (ideal reporting and audit driven compliance with core standards); (iv) extraneous factors stemming from beyond the health system (national vocational training leading to national shortage of plumbers); and (v) an overall lack of systems thinking.

\section{Conclusions}

South Africa needs to be applauded for adopting UHC. Noteworthy among factors fueling policy-practice gaps are human factors, perception and responses of actors in the system to a lack of resources, processes and systems, through among others, ideal reporting and audit driven compliance with core standards, bringing about an additional layer of unintended consequences, further widening that gap. Utilizing a systems approach to address challenges identified, could go a long way in making UHC a reality.

South Africa, like many other countries, is currently piloting National Health Insurance (NHI) reforms and policies aimed at achieving health for all, Universal Health Coverage
(UHC). The once obscure idea of UHC has blossomed into a movement embraced by leading authorities in global health. ${ }^{1}$ Different countries are taking different routes to 
achieve universal health coverage. Thailand for example, introduced UHC in 2001 and became one of a few lowermiddle income countries to do so at the time. ${ }^{2}$ Universal coverage is defined as ensuring that all people obtain services they need, of good quality, without suffering financial hardships when paying for them. 3,4

The South African rationale for introducing NHI is to eliminate the current two tiered system, where those with the greatest need have the least access coupled with poor health outcomes. ${ }^{5}$ Such differences make the South African Health System fall short of the goal of UHC both in relation to financial protection, equity in financing, equitable access and good quality health care. ${ }^{4}$ Primary health care (PHC) is the approach the South African government adopted in 1994 to deliver health care. ${ }^{6}$ Insufficient attention was given to the implementation of the PHC the first time resulting in a neglect of taking comprehensive services to communities, disease prevention, health promotion and community participation ${ }^{7}$ hence the renewed focus on reengineering PHC. 5 Some of the major challenges facing PHC include inadequate political, financial, human and material commitments, optimal use of available resources, changing management techniques including decentralization and ensuring effective community participation and intersectoral collaboration. ${ }^{8}$ Historical imbalances coupled with changing patterns of disease and complex burden of communicable and non-communicable diseases also place a huge strain on the public health services in South Africa. ${ }^{8}$

The public health system in South Africa currently suffers from an implementation gap-good policy on paper and poor translation on the ground. This is a similar case for other public services such as energy, water, sanitation and housing. ${ }^{9}$ Leadership failures, poor stewardship and weak management have been identified as some of the factors affecting policy implementation. $5,6,10$ Public or govermnet policy is defined as what the government chooses to do or not to do. ${ }^{11}$ The discrepancy between policy and practice has been a subject of concern and fascination to academics, policy makers, implementers and users alike. Discrepancies between policy and practice may be attributed to inadequacies both in policy development and implementation. Policy failure can result from bad policy, bad execution or bad luck. ${ }^{12}$

Policy implementation is defined as the mechanisms, resources and relationships that link policies to program action. ${ }^{13}$ Too often policy assessments emphasize outputs or outcomes but neglect the policy implementation process, which could shed light on barriers and facilitators of effective implementation. ${ }^{14}$ Assessing policy implementation process opens up the black box to provide greater understanding of why programs work or do not work and the factors that contribute to program success or failure. ${ }^{13}$ Has the intervention had limited effects because of weaknesses in its design, communication or implementation? ${ }^{14}$ Capturing what is delivered in practice with close reference to the theory of intervention can help ascertain the policy-practice gap. ${ }^{14}$

\section{PURPOSE AND SIGNIFICANCE OF STUDY}

Challenges faced by actors during the implementation process are numerous. ${ }^{6-8,12,13,15,16}$ We reckon that while it is important to identify challenges faced by actors during implementation, which tend to also vary according to context, ${ }^{17}$ that on its own does not explain how the presence of these challenges lead to policy practice gap. Very few systems are set up for the purpose of monitoring and tracking policy implementation in low to middle- income countries, capturing how and why they fail or succed. ${ }^{18}$ Few studies have focussed explicitly on developing a qualitatitive understanding of the experiences of those at the decision-making level (province, district) and (facility) frontline, comparing and contrasting their implementation experience of the same policies (UHC). In this paper, we focus on presenting the perspectives of both policy makers and policy implementers. Very little is also known on what actors (policy makers and policy implementers) do when faced with policy implementation challenges in their day to day work, and how actions undertaken, may lead to a policy-practice gap. This research is a broader attempt to cover that gap in research. This paper uses contextual interaction theory (CIT) model to extensively show how actor characteristics influence policy implementation and how they inturn influence each other. ${ }^{17}$ Even though the CIT graphical model pays attention to the interaction between key-actor characteristics, they were never before really used in empirical research to create a more holistic view of the implementation situation. ${ }^{19}$ This is one of the first attempts to demonstrate a graphical model paying attention to the interaction between key actor characteristics using empirical research in a UHC context.

\section{CONTEXTUAL INTERACTION THEORY: A CONCEPTUAL FRAMEWORK}

The complexity of the policy implementation process has challenged researchers to develop theories and models, albeit with a limited number of explanatory variables that predict how and under what conditions policies are implemented. ${ }^{20,21}$ Scholars have agreed that implementation is far too complex to be accounted for by a single theory. ${ }^{22}$ On the other hand a theory or model provides a framework for systematically identifying and reporting factors implementers perceive as affecting the implementation process. ${ }^{21}$ We identified the $\mathrm{CIT}^{17}$ as it provides a relatively simple, empirically tested framework for identifying fundamental issues underlying barriers within an implementation network. The basic assumption of the contextual interaction theory is that the course and outcome of the policy process depends not only on inputs but more crucially on the charactersitics of the actors involved particularly their motivation, power, resources and interactions. ${ }^{23}$ All the other factors that influence the process do so because of and in so far as they influence the characteristics of the actors involved. The theory does not deny the value of multiplicity of possible factors, but claims that theoretically, their influence can be best understood by assessing their impact on motivation, information, power, resources and interactions of the actors involved. ${ }^{17}$

The discussion of actors includes policy makers at provincial, level where the task of operationalising NHI reforms had been assigned ${ }^{24}$ and policy implementers at district, subdistrict and facility levels in the primary health 
care system. One of CIT`s key assumption is that factors influencing implementation are interactive. The influence of any factor, whether positive or negative, depends on the particular context. The theory distinguishes a set of core constructs or concepts related to the actors involved which jointly contribute to implementation. Core constructs are:

Motivation: The level of importance the actors place on a policy and the degree to which policy contributes to their goals and objectives affects implementation. If actors have low motivation, they may ignore implementing the policy. Examining motivation helps to understand the perspectives of implementers, their belief system, value priorities and perception of the importance and magnitude of specific problems often revealing root causes of implementation barriers. ${ }^{21}$

Information: Successful policy implementation requires that those involved have sufficient information including technical knowledge of the matter at hand, levels and patterns of communication between actors. For example, do those responsible for implementation actually know with whom they should be working and who the policy should benefit? Do they know which department is assigned to lead the implementation and how the programme will be monitored? How is information and communication between actors coordinated? Have guidelines been developed and are they readily available?. ${ }^{17,21}$

Power: Who is empowered to implement policy and to what degree? Power may derive from formal sources such as a legal system eg, appointment or from informal sources such as charisma or being an elderly.

Resources: Having adequate resources for the intended action is important for actors to realize policy implementation goals. Resources provide the capacity to act. ${ }^{24}$ The relevance and availability of resources influence the actors motivation which in turn influences the whole policy implementation process. ${ }^{25}$

Interactions: interactions predict the level of collaboration among and between actors which in turn influence policy implementation. They must be considered to further analyze barriers to implementation. These interactions can take different forms from cooperation, passive cooperation, forced cooperation, opposition or joint learning. Inturn actors collaboration depends on how they percieve the problem being addressed as a priority, how convinced they are that there is an acceptable solution, that taking action now is in own best interest and if they have implementing capacity. ${ }^{17,21}$ Specifying the above constructs facilitates the developmemt of tools to measure the level at which each of the core construct contributes or hinders implementation. ${ }^{21}$ These central CIT tenets guided our analysis and interpretation of findings in this study.

\section{METHODS}

A qualitative, exploratory case study design utilizing a theory of change (TOC) approach was followed to explore universal health coverage policy implementation experiences. TOC is a theory of how and why initiatives work. ${ }^{26}$ TOC is a tool that describes assumptions actors have, explains steps and activities they take to achieve goals and connections between these activities and the policy outcome. ${ }^{26}$ Thus, theory of change allowed actors at provincial, district, subdisrict and facility levels to reflect on their assumptions, perceptions and experiences in the implementation of policies aimed at achieving UHC. An iterative, inductive and deductive data analysis approach guided by contextual interaction theory was utilized.

\section{RESEARCH SETTING AND SAMPLING}

Ten pilot districts were identified by the department of health and selected as national health insurance (NHI) pilot sites. The national department of health $(\mathrm{DoH})$ selected these sites based on poor performance on key health indicators like high maternal and child mortality rates. ${ }^{27}$ Universal Coverage in Tanzania and South Africa (UNITAS) purposively selected three out the ten selected NHI pilot districts in South Africa. A case study design was used for this research. A case study design is defined as an empirical inquiry that investigates a phenomenon within its real-life context. $^{28}$ This study is situated in only one of the three districts, district $\mathrm{X}$ (name withheld for anonymity reasons). The case was the district $(\mathrm{X})$, conveniently selected as the only NHI pilot district in that province at the time. Managerial support and willingness to participate in the study also guided site selection.

\section{STUDY AIM}

The study aimed at tracking NHI policy implementation process through the engagement of policy makers and policy implementers in order to explore, identify and describe why and how policy-practice discrepancies come about in UHC context.

\section{CENTRAL QUESTION}

"What bottlenecks and challenges are you experiencing in your current role as a UHC policy maker/ implementer? (Information, motivation, power, resources, interactions and others)."

\section{SUBQUESTIONS}

"How and why do discrepancies between policy and practice come about from your (actors) current policy implementation experience. Identify and describe an instance(s) in the course of duty, where you (actor) or colleagues deviated from policy?"

\section{DISTRICT HEALTH SYSTEM DESCRIPTION}

A district health system (DHS) is the cornerstone of the South African health system. ${ }^{5}$ This is a geographically demarcated area with health care facilities to serve that population. Primary health care facilities serve as the first point of contact with the health system, followed by community health centres (subdistrict), which are slightly bigger, with resident doctors doing minor surgeries like caesarean sections. Cases that cannot be handled at this level are then transferred to the district hospital, run by a hospital management team under the leadership of a chief executive officer. The district itself is run by a district health team, 


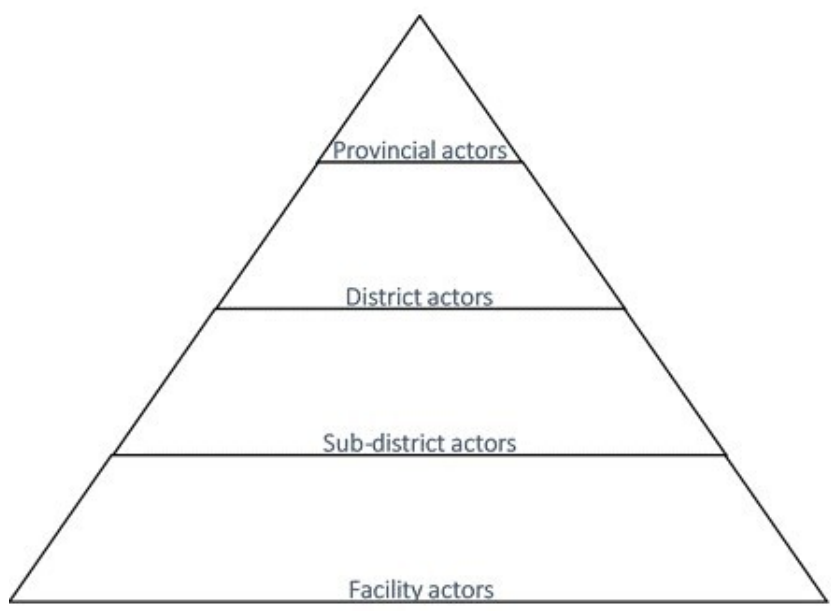

Figure 1. Level of health system actors represented.

headed by the district manager. She is supported by programme managers, primary health care supervisors and subdistrict managers among others, to provide support to health facilities. The district manager reports to the provincial authorities who in turn report to national authorities.

\section{RESEARCH PARTICIPANTS}

Key informants ranged from provincial actors (policy makers) where the task of operationalising NHI reforms had been assigned, ${ }^{24}$ and district, subdistrict and PHC facility actors (policy implementers) (Figure 1). Purposive sampling of actors at provincial and district levels was based on, their knowledge and involvement in NHI activities, their availability at the times of interviews and willingness to participate. From district to PHC facility level, all actors were involved in NHI policy implementation and the district and subdistrict managers further assisted in the purposive selection of these key informants. Senior management, doctors and nurses from one district hospital, two community health centres and 10 PHC facilities were involved in the study. No patients were involved since their role in policy implementation is limited. See Table 1 for key informant summary.

\section{DATA COLLECTION}

Qualitative data were collected during three phases 2011-2012 (contextual mapping), 2013-2014 (round 1) and 2015 (round 2). A theory of change approach was employed. In-depth face to face interviews were held with participants using a theory of change interview guide adapted for each phase (Appendix S1 in the Online Supplementary Document). This was informed by an iterative process of data collection and engagement with actors from contextual mapping through round one and two. Interviews took place in departmental offices and buildings where the actors worked, at a time suitable and agreed to by participants. The duration of each interview varied from 2-3 hours. Two researchers at every occasion, conducted the interviews in English. All participants were qualified professionals who had no problems understanding or responding in English.
UNITAS obtained full ethical approval for the study granted by the University of KwaZulu-Natal biomedical research Ehics Committee; REF BE197/13. Support letters were provided by the provincial and district offices in our study site. All interviews were audio-recorded. All participants gave informed and signed consent and were free to withdraw from the study at any time.

Contextual mapping was carried out before the roll-out of NHI policies (2011-2012). The goal of this phase was to assess the readiness of the district to rollout NHI policies. At this stage, only senior participants at provincial, district and subdistrict level $(n=5)$ were interviewed using a semistructured theory of change interview guide. Open ended questions were used to explore participants' knowledge of NHI policies, knowledge of beneficiaries, assumptions held, challenges on the ground and activities they had planned to translate policy into practice. (See Appendix $S 1$ of the Online Supplementary Document for interview guide).

The first round (2013-2014) interviews involved actors from province to PHC facility level. Interviews were held approximately one year after NHI policy roll-out, and the goal of round 1 interviews was to elicit the experiences of policy makers and implementers one year into policy implementation. Utilizing the theory of change interview guide, we explored their understanding of NHI, who the intended beneficiaries were, their assumptions as well challenges they were experiencing including challenges with regards to Information, Motivation, Power, Resources and Interactions. Provincial, district and subdistrict actors interviewed during contextual mapping were also interviewed during round 1 . At hospital and community health centre (CHC) levels, management including senior doctors, operational managers and clinical staff took part in the study. At PHC facility level, operational managers and at least two other PHC nursing staff were interviewed $(n=37)$. Occasionally, through-out the research, a facility data capturer was interviewed to fill the gaps on statistical questions like PHC head count, whenever the nursing staff were unsure.

The second round was carried out in 2015. The research took place in a context of provincial moratoria on human resource recruitment, hence there was considerable high staff turnover and human resource shortages. ${ }^{24}$ During this round, a new provincial NHI actor was interviewed. She herself was already on her way out as she had also just resigned. Most of the district actors from first round were interviewed, excluding one manager who had resigned and a senior one who had no time. The same subdistrict actors and many PHC facility managers and staff took part in this round $(n=29)$. Despite the high staff turnover, including resignations and the death of one PHC operational manager, many participants were interviewed at least twice during the 5 -year period. The goal of round 2 was to elicit from actors what they had achieved in terms of NHI policy implementation during this period. We explored with each participant, what had transpired since our last visit and what the participant had achieved in terms of activities they had planned to carry out. If they were successful, we explored for factors that facilitated implementation and if they failed to carry out the planned activities, we also explored for factors that hindered implementation. Its important to highlight that there were cases of successful pol- 
Table 1. Overview of key informants, research phase, role and where they worked (health system level)

\begin{tabular}{|c|c|c|c|c|c|}
\hline $\begin{array}{l}\text { Health } \\
\text { system } \\
\text { level }\end{array}$ & Role & $\begin{array}{l}\text { Contextual } \\
\text { mapping }\end{array}$ & $\begin{array}{c}\text { Round } \\
1\end{array}$ & $\begin{array}{c}\text { Round } \\
2\end{array}$ & Total \\
\hline Provincial & Policy maker -making sure NHI policies are carried out & 1 & 1 & 1 & 3 \\
\hline District & $\begin{array}{l}\text { Policy implementers ranging from district manager, } \\
\text { programme managers, district clinical specialist team, } \\
\text { Emergency rescue service manager and PHC supervisors } \\
\text { with policy implementation responsibilities including the } \\
\text { PHC supervision manual }\end{array}$ & 1 & 5 & 4 & 10 \\
\hline Subdistrict & $\begin{array}{l}\text { Policy implementers at subdistrict level ranging from CEOs } \\
\text { managers, nurses and doctors implementing policies aimed } \\
\text { at UHC as well as providing direct patient care }\end{array}$ & 3 & 12 & 8 & 23 \\
\hline $\begin{array}{l}\text { PHC } \\
\text { facility }\end{array}$ & $\begin{array}{l}\text { Policy implementers including operational managers and } \\
\text { staff in PHC facilities implementing policies aimed at UHC } \\
\text { as well as providing direct patient care }\end{array}$ & - & 19 & 16 & 35 \\
\hline Total & & 5 & 37 & 29 & 71 \\
\hline
\end{tabular}

PHC - primary healthcare, NHI - National Health Insurance

icy implementaion that were achieved, for example central chronic medicine dispensing programme (CCMD) ${ }^{29}$ but since the focus of this paper is on policy-practice gap, these will not be presented in this paper.

\section{DATA ANALYSIS}

Interviews held in all three phases, contextual mapping, first round and second round were audio-recorded, transcribed and coded for emerging themes. An iterative, inductive and deductive aproach was utilized. Transcripts were coded with the aid of MAXQDA2018. Trustworthiness criteria were used to evaluate rigour for this study. ${ }^{30}$ Trustworthiness concepts included dependability, credibility, confirmability and transferabilty. To ensure dependability we described data collection process in detail and two researchers experienced in qualitative methods, kept reflexive individual journals through-out data collection and analysis. Debriefing after interviews was done daily in the field. The two researchers further analysed the data independently before reaching consensus under the supervision of an experienced qualitative researcher. To ensure confirmability findings were discussed with supervisors and co-authors experienced in the field, and their responses were incorporated. To enhance transferability, participants, context and process of analysis have been described in detail. 30 We achieved data saturation ${ }^{31}$ and data source triangulation, through interviewing actors from different levels of the health system.

\section{RESULTS}

We present the perspectives of actors from every level of the health system starting from provincial, district, sub-district to facility level comparing and contrasting actor experiences, meaning and perceptions with regards to policy implementation experiences and how policy-practice gaps come about. Deductive themes, CIT constructs and inductive themes (emergent themes) were so connected and interrelated, so much so that presenting them separately would have led to a loss of data and relationships, critical in demonstrating the nature and level of complexity our findings revealed. Below we discuss these deductive themes highlighting connections, interconnectednesses as well as inductive themes.

Findings are firstly presented according to CIT constructs (information, motivation; power, resources and interactions), then a presentation of inductive themes generated in the analysis is presented. Both deductive and inductive themes were further categorized into five groups namely: primary, secondary, tertiary, extraneous factors and an overall lack of systems thinking.

i. Primary factors stem from a direct lack of a critical component for policy implementation, tangible or intangible eg, human, infrastructure and material resources, information, motivation, power).

ii. Secondary factors stem from a lack of efficient processes or systems (budget processes, limited financial delegations, top down directives, communication channels, supply chain processes, ineffective supervision and performance management systems).

iii. Tertiary factors stem from human factors (perception and cognition) and calculated human responses to a lack of primary, secondary or extraneous factors as coping mechanisms (ideal reporting and audit driven compliance with standards as a result of policing supervision).

iv. Extraneous factors stem from beyond the health system (national vocational training leading to national shortage of plumbers), and

v. An overall lack of systems thinking. Systems thinking is a disciplined approach to examining problems more accurately and completely before acting, bearing in mind interconnectedness, moving from observing events to identifying patterns of behaviour over time, to reveal the underlying structures driving those events and patterns. ${ }^{32}$

The five groups are presented in the discussion section followed by diagrammatic representations of relationships alluded to by participants. Diagrams are not exhaustive of all relationships mentioned. 


\section{CIT TENET: INFORMATION}

Many participants were aware of the fact that they were a pilot site but lacked details of what their roles were. The most informed were those who had attended the Minister of Health road shows. They demonstrated an understanding of what NHI meant and were typically provincial, district and some senior facility actors that had been handpicked to attend the meeting with the Minister. The human factor seemed to play a role here. Access to information seems dependant upon seniority, who delivers the information (eg, Minister) but also how the information is delivered seems to matter, if it is to be effective (in this case face to face). Below is what a participant said:

\begin{abstract}
"Well in terms of the NHI, we had the first Doctor Motsoaledi s road show. Well, I understood that they are looking at equal healthcare for everybody. We've also been motivating that for our patients. We also understood that, at some time, by 2014, everybody will be receiving the same healthcare. Right now, we've got the private sector, who are performing at a very high, a much higher level than us, but that's because they have all the resources and things like that. So, hopefully one day, we will also be able to perform at that level, and offer that high-quality care to our communities." - district actor contextual mapping.
\end{abstract}

Attending the minister's road show helped participants understand what NHI meant but even some senior participants left the road show unclear of what it meant to be an NHI pilot site as revealed by one participant below:

\begin{abstract}
"For me I always think it is a challenge that we are told we are a pilot, but we are not in essence a pilot site. Yes, we are a pilot site, but we are not piloting, because if you are a pilot site, I think it says you must try things that have never been done before, and see if they are working or not working. We cannot be guided by the same principles like the other sites, that are not piloting. If we are told that we are pilot site, but we are still being guided by same guidelines and policies, that guides other people, so we are not piloting. Because if we are a guinea pig, then they must allow us space to say we can try this and I can then say I tried this, it worked, I tried this, it did not work because of one two three, but now being in this environment, we cannot try something because we are confined." - district actor contextual mapping.
\end{abstract}

Many frontline actors who did not attend the road shows not only demonstrated little understanding of NHI but were also not clear of their roles in this regard from round one throughout to round two when the study ended. Below are excerpts from subdistrict to facility actors during round one through to round two.

"Us here on the ground and I wanted to come to this. we don't liaise with people from the province, we only liaise with people from the district. With the district manager and the other people, so we don't know much on the level of the people in the province and so on, but I don't think it (NHI) was introduced to us on the ground properly, we were just told this is NHI, its coming and we must do this. We did not understand what that means because most people couldn't tell us what that meant. So being a pilot site they would tell us this is from NHI budget and brought us new linen, new beds in which they put in one ward, which is known as the NHI ward, but you are not told what you are supposed to do. You get one or two renovations and new linen, and when the provincial Member of the executive council (MEC) and national come to visit, they take them to that ward, because it's been renovated and so forth, but the ground people do not know what they are supposed to do, for this pilot phase to actually succeed, they just think it's something that will happen so their work continues as normal on the ground" subdistrict actor round 1.

"We just heard on the radio that NHI is coming...but nobody came to us to explain what NHI means..." - facility actor round 2 .

"Yes, I will tell you, for instance, my understanding of NHI was to say, a patient can go wherever they want, whether private or governmental instituition, wherever, to seek care. The care would be standardised and any patient can go anywhere where one wants including private sector, get care, and the government will reimburse the private sector, and the standard of care would be the same in both private and public sector.The patient will have freedom to go wherever they want to go, and if the charges in private are higher, the government is going to subsidize the private sector. You see, that was my understanding of NHI. Now I have not seen that happening, you get that point? So, I might tell you that NHI is not happening because of that which was my understanding." - subdistrict actor round 2 .

\section{COMMUNICATION}

Communication was said to be one-sided, top down and ineffective, making access to information difficult as revealed below:

"Top down process, so the staff here are not consulted before the policy is finalised you see. Before the policy is finalised there should be quality discussions with all the relevant stakeholders. We only heard about NHI when everything was finalised... Everything is finalised, national adopts them then they send them to the province and then from the province to the district, district to the hospital and clinics they come." - subdistrict actor round 1.

Some participants proposed having change agents or supervisors, who could orientate them so as to implement policies effectively. Below are statements of participants in that regard:

"It's very difficult because right now they just do not visit us, if maybe they could orientate us, introduce us to these things nicely. But they don't do that, like the national core standards (NCS), they just pushed the files; they gave us the files in one of the meetings. We didn't even know what these files were for, what the content was. It was only after some time, that they came and asked for NCS and said check in your red file, check in your green file. It was then that we noticed "oh there is the red file." - facility actor round 1 .

"We lack support of our district office. We need the devolution of power, if they could give power to us- they form these long lines of communication, that doesn't work for us and often they make agreemenst without involving us." - facility actor round 1 .

"The communication is very poor. There is no communication. I mean if they want us to put all this into practice, we need staff to go for training. They have got a big file 


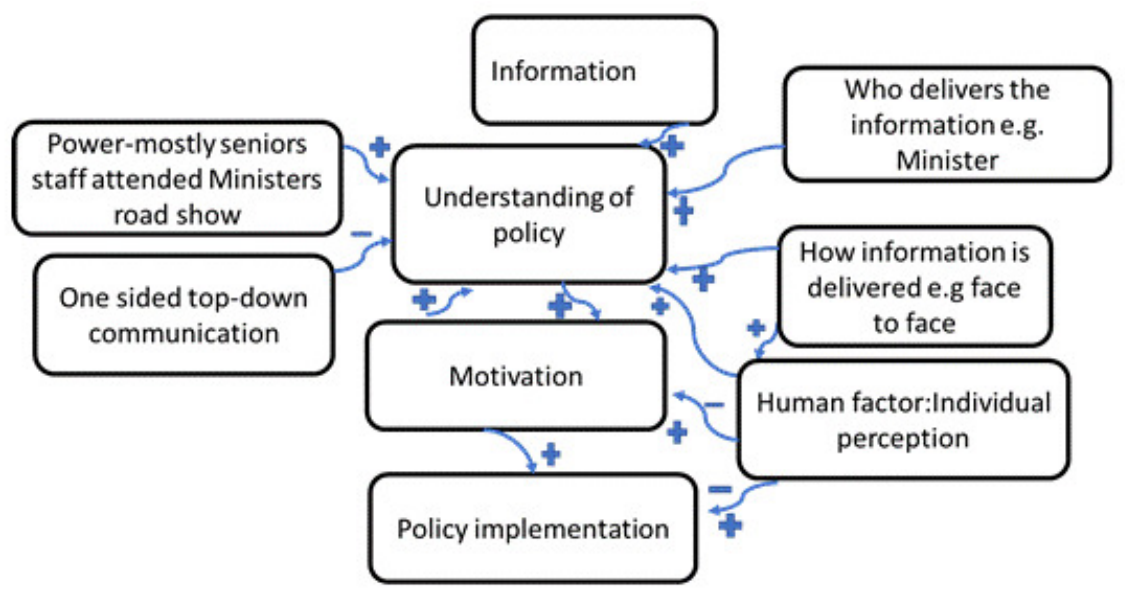

Positively influences factor in direction of arrow

- Negatively influences factor in direction of arrow

+ - Ifluence can go both ways, it depends...

Figure 2. Summary depiction of information led policy-practice gap.

here. National Core Standard file. They want us to do audits, but we have not been to a workshop to show us how we should go about it. I do not know if what I am doing is right or wrong." - facility actor round 2 .

"What happens is that people at management level go to these meetings (workshops and road shows) but the people on the ground us, are expected to implement, but we have not been trained." - facility actor round 2 .

\section{HUMAN FACTOR-PERCEPTION}

The human factor was revealed to play an important role in policy implementation. Of interest is the role of perception. Exposed to the same information and format of communication, face to face, actors understanding of NHI and roles differed. Policies with high levels of ambiguity or conflict can lead to non-implementation. ${ }^{33}$ Two team members, who received the same orientation training, had at the end a totally different understanding of what their roles in policy implementation were, with one saying clinical role and the other administrative role. These perception differences seem to be affecting the policy-practice gap. See Figure 2 below for some of the relationships and connections alluded to by participants.

\section{CIT TENET: MOTIVATION}

The announcement of NHI brought hope to many South Africans and professionals alike, and this NHI optimism could be felt during contextual mapping as revealed by one participant below:

"You must really appreciate that there is progress that and also within the programme, the NHI, there have been clinics, that have been identified as ideal they are called ideal clinics, prototype where there is a lot of support to make them benchmarks for the rest of the other clinics in terms of implementation of the national core standards, in terms of the queues in the clinic, in terms of the infrastructure, how should it look like, so there is a lot of support from national to ensure that these clinics become the benchmark for the rest of the district, so we are fortunate that in this district, there are three clinics that are actually receiving support." - district actor contextual mapping.

\section{HIGH INTRINSIC MOTIVATION}

During both rounds one and two, most facility actors exhibited high intrinsic motivation with some facility actors reporting acting against policy, so as to ensure good patient outcomes at the risk of prosecution eg, by taking patients to hospital in own cars when ambulances did not respond.

\footnotetext{
"If it demands that you take the client in your cars every day, you just do it for the sake of the client you know." facility actor round 1 .
}

Love for patients, their work and support from family as well as faith, were expressed as factors that motivated staff to come to work during both rounds one and two as revealed below:

"I like my job...also, my clients, I love them. They motivate me because they are not giving me a headache... I just like interacting with patients...."

- facility actor round 1

The things that make me come back to work is, I think of the patients... my daughters as well, I have two daughters who are very supportive and very understanding.... and support from my church as well. Yes, prayers you know, are a strong resource to fall back on." - facility actor round 2. 


\section{CIT TENET: RESOURCES}

All facility actors expressed how the unresolved challenges and seemingly lack of support and solutions from the top, were eroding their motivation. These challenges ranged from equipment, human resources, infrastructure, maintenance, and material shortages. Actors at provincial, district and facility level had often varying perspectives on the same issues as revealed below.

\section{HUMAN RESOURCE CHALLENGES}

"Yes, for NHI, if you're asking about resources for NHI, within the period that I've been here, I think we have more than enough resources. It's a question of how we use the resources. You go to facility $A$ and facility $B$. The bed occupancy rate here (Facility $A$ ) is consistently around about thirty per cent and fifty per cent. The bed occupancy rate here (Facility B) is probably let's say around seventy per cent. Because they in government have a generic approved organisational structure, you still have the same number of nurses in both facilities. What is it that they are doing if these organisational structures were designed for a two hundred and fifty bedded hospital, which is consistently operating at a hundred births per year? Compare the clinics that you're having in your area. We have the resources. Some of them are fine, well utilised. I went into another facility and found there were more nurses than patients on the ward, but these patients were lying in the beds-neglected. We went to another facility, we took a walk about and this was a maternity ward. The nurses were having their ankles swollen. They'd been standing the whole day since morning, since they reported on duty. They were actually grabbing their tea whilst working because probably unfortunately we came on the wrong day. We left that ward. We went to the surgical ward. We found nurses sitting at the nurses' station. They said to us now we are done with our said rounds. The doctors came in the morning. We gave patients their medication and we did everything and so they sat at the station. You have a nursing service manager, unit managers that have been doing rounds. They can't take the decision to say, today the workload is this, let us move nurses from the quieter ward to this side-busier ward. So those are the issues until such time we manage those systemic issues. So, to answer the question of resources, we can say, now we have more resources, the question is how much are we losing on the wastage?" - provincial actor round 1 .

"...we are so short-staffed, because every month it seems somebody is resigning or retiring and with the workload and all that the staff is so few. It's worse if you work in Room 5, there's too much, you become mentally exhausted. You are constantly seeing patients, you are mentally exhausted and then your stress levels are high and then you find out your colleagues, some of them are not on duty because they are burnt out, and then the strain is on you." - subdistrict actor round 1 .

"Shortage of staff, it's the main challenge here." - facility actor round 1 .

During round two most facility actors expressed human resource shortages as dire to the point of affecting their well-being, quality of care and fuelling staff patient attitudes as revealed below:
"I think it is very demoralising for the staff. It causes a lot of heart ache... and besides demoralising them, it increases the absenteeism rate, they get sicker, they get more tired. It impacts on their attitude towards patients, because they come in day in and day out. They are seeing the same thing and they know that they actually have no control over it. You cannot say to the patients, today I am only one so I can only see ten patients. If there is 100 you have got to see to 100. She is going to miss something out you know, so it does have an impact and also affects the expectations of the patients. You know I have come to you. I do not care whether you are a tertiary, regional facility or whatever. I have come to you, so if I need brain surgery who must do it for me? You know so that whole thing is not understood that well. So, it is as if the staff get squashed in the middle of expectations from higher up and expectations from the patients. That is inturn resulting in the high staff turnover, staff getting fed up, increase in adverse events, increased absenteeism and all of that." - subdistrict actor round 2

"What is your level of accuracy when you are seeing $100 \mathrm{pa-}$ tients and what is the standard of care? I can see a person and give them five minutes of quality care but by the time I have seen patient 60 I am exhausted and I am moving from one program to the next program to the next and I am getting muddled up." - subdistrict actor round 2.

\section{STAFF SHORTAGES AND ABSENTEEISM}

Some expressed how being overworked was leading to absenteeism consequently creating a vicious cycle as expressed below;
"Staff shortage affects us a lot. Beause, as you see till now, we have not had breakfast. ...we don't have tea. Be- cause of that sometimes you end up not doing a patient assessment thoroughly because of overload, you know. So sometimes, while I'm doing HIV counselling and testing (HCT), I have to check the patient status, I have to do a pap smear, I have to do all the other requirements for the patient. Maybe it takes an hour or 45 minutes. So, the patients end up complaining, we are working slowly, you know, they don't understand." - facility actor round 2.
"Because of the staff shortages, you know what needs to be done on the patient, but sometimes you simply do not do it, because you don't get time. You are always over worked, so you would rather stay absent from duty or go see a doc- tor, so that you can do your own things sometimes" - fa- cility actor round 2 .
"...maybe because of the shortage of staff and too much work, people get demotivated and decide to stay away and be sick sometimes, when they need a break. I think they are burnt out. Yes, because even me, I get so much of burnout. If I could, I would go and get admitted and lie down for two days in hospital, you know. Well, I can't because things will fall apart here. So, I have to be here every day. I have backache, I'm struggling and I come in pain anyway." - facility actor round 2 .

\section{INFRASTRUCTURAL CHALLENGES}

Some policies dictate that the patients be treated separately and yet some facilities do not have the sufficient space. Infrastructural challenges were revealed as a major stumbling block, preventing many actors in this district from imple- 
menting certain policies for example, the three streams approach, where patients with different ailments follow different queues, so as to reduce cross infections. Provincial, district and facility actors shared the same concern as revealed below:

Some facilities, particularly primary health care facilities have a challenge and with the extension of programmes now like my colleagues are correctly saying, the old clinics were structured in such a way so as to take care of the preventative components like family planning and immunisation and now with HIV and the ARV clinics, there are so many problems and we need more space." - district actor round 1 .

District actors not only acknowledged these infrastructural challenges but also expressed helplessness in that regard as revealed below:

Otherwise other challenges are beyond us, like the infrastructure ... because when you go there (to facilities), they think you are coming with all the answers and yet you are not, because really, I think even the way how to handle that, is not very clear to us, except to say write some motivational letters for this. We try to enforce them to do their work wherever they are. They should use whatever resources that they have at that time. But in other situations, you can see that really you are forcing them to do something that is impossible. There is no space. When you are talking about infection control, we too see that what we ask of them really, becomes unrealistic." - district actor round 1 .

"What I am saying is that infrastructure, as much as we can recommend, it is not within our control. We can recommend that is the best I can do, or say send a motivation letter there, but it is a process and the structures in our district, are built in phases actually. There is phase one up to phase five and even if you want the clinic to be built, but the clinic falls under phase five, that is long term. So, you can recommend but we cannot control that." - district actor round 1 .

"This is a very old clinic and we are expected to implement the ideal clinic; the infrastructure does not allow for that. In the ideal clinic, you have to divide the clinic into three streams, chronic, minor ailments and mother and child. But looking at this infrastructure, it does not allow for such. We've tried to divide the clinic into three streams, and ended up not having space for the chronic part. We ended up dividing chronics into two, non-communicable and communicable on the other side." - facility actor round 1.

\section{LINK BETWEEN BUDGETS, INFRASTRUCTURE AND QUALITY OF CARE}

Infrastructure was said to be affected by limited budgets but actors also pointed out how infrastructure in turn affected quality of care and infringed on patient privacy as follows;

\footnotetext{
"Yes, there are some challenges in this clinic. The problem we have is spacing, the consultation rooms are few in such a way that you will find there are two nurses consulting in one room because the space is just limited. We do not have a separate dressing room or immunisation room, so we are using one room for family planning and immunisation because of space constraints." - facility actor round 1.
}

"Infrastructure: that is the major lack and it impedes on the staff work and daily activities as well. The district is not building a new structure as there is no budget for it." subdistrict actor round 1.

"We don't have space-the problem is infrastructure. We don't have places to work from. There are not enough consultation rooms. Even if I get additional staff one particular day, there is nowhere I can put them since the fourth consulting room is the one that is used by the doctor and other days an optometrist." - facility actor round 1 .

A new initiative, having doctors come into the clinics had been initiated successfully as part of NHI policies, but infrastructural issues had not been taken into account affecting quality of care like privacy in counselling as revealed below;

$$
\begin{aligned}
& \text { “...even the room for the Doctor, there's no space, he is us- } \\
& \text { ing the room for the counsellor. The counsellor will go out } \\
& \text { and squash somewhere." - facility actor round } 1 .
\end{aligned}
$$

\section{DELAYS IN COMMISSIONING OF NHI BUILDINGS}

Some facilities got new NHI buildings (new clinic models funded through conditional grant) during round one and two. Some of the buildings however, were still locked up despite completion. It was not clear who would and when the buildings would be handed over to the clinic OM for use. District actors acknowledged the issue but seemed not to know who had the keys.

$$
\begin{aligned}
& \text { "Yes, we were at one clinic [name withheld for anonymity], } \\
& \text { they have a new building, but it has been locked, under } \\
& \text { lock and key." - district actor round } 2 .
\end{aligned}
$$

Facility actors on the other hand thought the district was responsible and kept calling to no avail as revealed below:
"What I know is that there are rooms that side they need to be opened so that we can function... because patients are complaining, those who are collecting ARVs, they're complaining anyone, anybody who comes here will know that they are HIV positive. because all those people who go down there are collecting HIV tablets. So, that building is completed, we don't know why we're waiting for so long for it to be opened. We want everyone to get seen under one roof, Hyperten- sion, ARV patients, so that no one can say that one is here for ARVs and the other one for that. That's NHI, I don't know why we are waiting, because everything is there-fully equipped. The operational manger $(\mathrm{OM})$ used to call the District Office, but they keep on saying they are coming, they are coming. Nothing, all came to no avail." facility actor round 2.

LINK BETWEEN DELAYS IN COMMISSIONING BUILDINGS AND QUALITY OF CARE

Elsewhere, the general practitioner (GP) was working from a very small dark room despite a ready, but similarly locked up new NHI building, raising fears of probably putting patients at risk as revealed below;

"Someone (the GP) now comes out here, he is in that small room, it's like a toilet room. He's working there, small room, without a light. We have sent several requests, that we are short of light bulbs to no avail. He's working in the darkness, in that small room, squashed. It's very difficult. 
I don't know actually why they don't open the new building., I think it's department of health. How then can we put this ideal clinic idea together under conditions such as these." - facility actor round 2 .

\section{LACK OF FRONTLINE STAFF INVOLVEMENT AND SHORTCOMINGS WITH SOME NEW NHI BUILDINGS}

Some of the new NHI buildings had permanent shortcomings facility actors felt would have been prevented had they been involved as revealed below;

"Although you know, there is one thing that I would like to see. I wish this new building, they built for us...I wish they could involve nurses in future when they build. I want to say something about this particular building, the door is high up from the veranda. I have had two patients fall and fortunately there were students around who caught them early otherwise they would have landed with bruised faces on the floor." - facility actor round 1.

The actors at subdistrict echoed similar sentiments on how infrastructural challenges were affecting implementation of policies such as national core standards as follows;

"Infrastructure. That is a very real challenge because in our NHI standards manual for infection control purposes and for us to be compliant, our patients are supposed to be at least 1.5 metres, apart, between beds. It is currently $0.5 \mathrm{~m}$, it is a half a meter. So, if we were to implement that standard, we are going to cut our patient bed state in half and we cannot afford that, because we always have full capacity. Our bed occupancy is like 100\% which is also exceeding the norm because it should be $75 \%$ in case there is an emergency." - subdistrict actor round 2.

\section{SHORTAGES OF BEDS AT REFERRAL INSTITUTIONS}

At hospital level, infrastructure challenges manifested in the form of bed shortages at regional and tertiary hospitals as revealed by many actors through out phases below:

"We, as a district hospital, deal with psychiatric patients but we are not supposed to keep them for more than 72 hours. It's observation only, for us. Then we refer them to the nearest hospital. Then we find ourselves having difficulties because we don't have a seclusion room as we don't have a ward for psyche patients. We mix psyche patients with medical patients - if it's a female - the female medical ward, if it's a male - the male ward, and then we find these patients now fighting the sick patients. The psychiatric patient ends up being here for more than three days. If we phone hospital $X$, [name withheld for confidentiality purposes], it will be the same story- no bed available, making the patient stay here for example more than five days in this hospital - so that's a problem." - subdistrict actor contextual mapping.

"That is still the same, you see. So many times, we are forced to keep the patient here because the regional hospital says no, we don't have any bed, keep the patient with you. They say when a bed is available, we will come back to you. We are keeping the patient for one day, two days, sometimes then the patients end up not getting transferred. Sometimes patients die here, other times patients complicate. And as a district hospital, we cannot say to the PHC don't bring the patient to us, you see. The tertiary then says to us keep the patient with you, okay. Or they say that they will give us advice, on how to manage patient you see. But then again, we don't have the necessary equipment you see. Sometimes the patient needs ventilation ... but now we don't have the ventilator machine here." subdistrict actor round 2.

\section{EQUIPMENT CHALLENGES}

Equipment challenges were expressed by all facility actors during both rounds while provincial and district level actors perceived the equipment situation favourably as revealed below;

"At least I can report now, that all of our pilot facilities have their basic essential medical equipment. At least in the pilot sites. We invested a lot in the last financial year on that part. At least with regards to essential medical equipment, I can say we are fine." - provincial actor round 1.

"Yes, equipment they all have... some provinces (elsewhere in South Africa) have run out of ARV's but we have not... so we are well-resourced in terms of drugs and equipment." - district actor round 1.

"For instance, when they come here, right now, we are supposed to have all the basic equipment in each and every room, for each sister. Unfortunately, they said they are still going to do that. So that when the patient comes to my room, I will have to do everything for her, and then she goes home. Instead of going to that room, to that room and to that room. She will come to me, I have got everything, I have got BP machine, CTG [cardiotocography monitors] everything, I will just attend to all her needs, write in her file, take history, examine her and give her the medication and return date. At the moment we don't have that, each room does not have all the basic equipment. I have got the BP machine, but other sisters, they haven't got ... CTG is there, but it is shared by all of us. So, we haven't got enough equipment for each and every professional nurse, so that when the patient comes to you, you can attend to all her needs and then she goes home." - subdistrict actor round 1

\section{EQUIPMENT SHORTAGE AND STAFF MOTIVATION}

Some actors pointed at how equipment shortages were inturn affecting staff motivation.
"It is very hard to work like this. It seems like we are com- plaining, you know, you cannot work when you have these challenges you cannot move forward. It is very difficult be- cause when they come (PHC Supervisors) they see that the equipment is not there (national core standards assess- ment on availability of equipment etc.) and then it is as if we are not doing our work". Well, it demotivates the staff, they are demotivated." - facility actor round 1.
"So instead if I had the equipment in my room, I could do everything the patient needs, but we do not have that amount of BP machines and glucometers. So, procurement of items takes very long. Yes, we do write a requisition form and then nothing comes." - facility actor round 2.

EQUIPMENT SHORTAGE AND WAITING TIMES

Some actors revealed how the shortage of equipment was also affecting waiting times and patient staff attitudes: 
"Yes, I have got it (proof of requisitions) in my file-yes. So, we are asking why is it always the patients' rights. What about the Nurses' rights and we are told to meet this target, meet that target, disregarding the fact that we do not have any BP machines? We have only got two in the clinic and there are five ${ }^{5}$ ) Sisters. There is one glucometer machine. There is one HB machine. ENT sets we only have 1, but it is not working properly. I have ordered all of that to no avail. If we do not have equipment how do you work? You are running around. Patients say oh the staff only knows how to run around, but we are running around looking for stuff [equipment in other rooms] for the patients." - facility actor round 2.

"We do not have sufficient equipment in all the rooms, so what happens is that the patient has to go to one room for BP measurement and to another for haemoglobin (HB) and all that -you know what I am saying? Then come to another room to get assessed. It increases the waiting time." - facility actor round 2 .

\section{SUPPLY CHAIN CHALLENGES}

Supply chain challenges were expressed at all levels, provincial through to facility level during all rounds. The complexity of the matter was also highlighted:

"Let me say, I'm not saying our supply chain systems are corrupt but out of the lessons I've learnt in the past months, I feel there's a need to review our supply chain processes and procurement processes. One of the questions I'm asking, why should I every time advertise to procure equipment for theatre for a hospital? I know very well that a hospital needs forceps. A hospital needs BP machines. Hospital needs all these so, why am I not engaging on a longterm three-year contracts with suppliers for that. You'll then understand that there's certain interest in there. So, those are the internal forces you have to contend with. I mean, I'm making an example of the procurement processes because everybody is benefiting. ... Can we change that? Here I have a responsibility to pilot this NHI for the first five years. Do I have enough time to also meddle in there...? I would say no, the system is too big, too big to change the whole system, the whole string of policies, and other core issues." - provincial actor round 1.

"The challenges lie with maintenance; we find that there is a problem and we report now and then. The toilets are leaking and when you phone or you send a job requisition, it takes long. For example, that waiting room, the door broke, you know. Even the pipes, they say they are waiting for managers, we are still waiting for new taps, meanwhile they are leaking. Even our staff toilet it is leaking." - facility actor round 1 .

"We've got a problem when it comes to ordering. It takes time, it takes ages to get the supplies we have ordered." facility actor round 1 .

"With obvious exceptions, but they don't move fast enough. They are not efficient. Anyway, I shouldn't be saying this. Well it is frustrating, but I think I've learnt working in the department of health, you have frustrations and you have to sort of roll with the punches. If you are going to get hot under the collar about every issue, you will end up with a heart attack and that will help nobody, so some of the general practitioners (GP's) came to me and said, oh how can you not have carbamazepine at the clinic, but what can I do about it? I complain to the pharmacists about it. She complains to head office. We just have to be a bit cool about it, because having a heart attack about it, is not going to help." - district actor round 2.

SUPPLY CHAIN CHALLENGES AND POLICY VIOLATIONS INCLUDING INFECTION CONTROL

Some actors expressed how they violated infection control principles due to material shortages as revealed below;
"For now, we don't have equipment. We don't even have delivery packs, if a delivery came here, we take everything we can lay our hands on, even unsterile stuff. Even though we do order sterile things, we often get no response, so we use expired packs, we put one for emergency, in case a de- livery comes and we use that expired one, you know." - fa- cility actor round 2 .
"Then we then said; 'Lets go back to the polices, now. Let's check all the policies under transport.' We phoned head office. They told us of the repatriation policy. It allows us to go and fetch the patient that has demised, but the chal- lenge - we don't have a dedicated, properly designed van, for fetching those patients. We use the normal one. It's like we are mixing things up, because I'm thinking of the waste now, also which is a challenge. We don't have a dedicated waste bukkie for the waste - I'm mixing. The waste is col- lected by us, from our satellite clinics on certain days, stip- ulated dates. As I said, there are six, there are going to be seven drivers, so we take our own guys, our own drivers - they go collect waste in the clinics with our ordinary vans. Whereas, according to the infection control standards, it is not accepted. The infection control practitioner always fights with us because that van will be used again, with- out any proper disinfection for other purposes you know- we have motivated for proper ones-no response till now." - subdistrict actor contextual mapping.

SUPPLY CHAIN CHALLENGES AS COMPLEX TO TACKLE

Supply chain, maintenance and shortage of medication challenges worsened during round two and staff showed signs of resignation. Some actors even viewed failing national core standards with a glimmer of hope, as may be the only way the national department of health could catch their attention and come to their rescue as revealed below:

"But those are bigger problems, for us supply chain will bring us down but that is why we are saying with all the audit processes, (national core standard assessments) sometimes failing is not a bad thing, because it actually brings attention to the areas and the gaps that we are having. So, we can say we are constantly failing on these. You national, you are getting our reports. You are getting our quality improvement (QI) plan. You are seeing the things that we are doing and it is not working, so now it is in your hands. What are you doing about it?”- subdistrict actor round 2.

"It is infrastructure and maintenance. It is massively frustrating. We have taken clinics over from the Municipality two or three years ago and they are still not painted and are delapidated. The department of health say oh no they are actually owned by the municipality, it's a municipal building, but we are all one government. I am ashamed to take people there, yet we are seemingly able to do nothing." - district actor round 2.

"That will remain a challenge I think forever until we retire. The processes, the SCM processes, they are actually an impediment to NHI." - district actor round 2. 
“..maintenance is very poor here...when you want something to be restored or to be repaired, maintenance takes ages. I don't have a suggestion box for four years, when we started the NHI. Brooms and mops broke, and we are expected to render services in a clean environment. maintenance and supplies are real issues." - facility actor round 2.

VICIOUS CYCLE OF INFRASTRUCTURE, SPACE, SUPPLY CHAIN, DRUG STOCKOUTS, HUMAN RESOURCES AND QUALITY OF CARE

Infrastructure was also associated with storage space, supply chain and drug stock outs. When facilities place an order for drugs or sundries, they do not always receive what they ask for and at the same time they cannot place too big orders in want of storage place. In one facility they sent the clinic clerk to follow up supplies that were ordered a long time ago on the day of interview. Duties of the clerk were transferred to security guards raising some quality of care issues. One facility had suspended child immunizations for longer than a week including day of visit, due to supply chain challenges as revealed below:

"And at the moment there are no plugs. The plugs are not working so we had to pack the cooler box, a box with immunisations. Put the ice bricks in it and send it back to CHC (name with held for anonymity reasons) and so we cannot dispense any immunisations in this clinic, because we do not have any plug points that are working for our vaccine fridge." - facility actor round 2 .

BUCKPASSING

Buckpassing with regards to supply chain challenges was revealed at all levels from provincial to facility levels. Other facilities that fell previously under the municipality, felt caught in between the municipality and the department of health with no-one taking responsibility for infrastructural upgrades and maintenance as revealed here;

\footnotetext{
"So, there has been a complaint about the clinic, the infrastructure for a long time and no-one is addressing it. They keep on shifting responsibility to the municipality and $\mathrm{mu}$ nicipality to $\mathrm{DOH}$. If there is a storm, our roof leaks and we have to clean up and still see patients in the dirty environment. One of the ceilings collapsed during a storm in there in the toilets. The ceiling is ripped. You can go and see for yourself. It is worse than a rural clinic. The conditions we are working under- there is no equipment. Still the same as it was last time you were here. No-one has done anything. The toilets are disgusting still broken down-just terrible working conditions." - facility actor round 2 .
}

The above sentiments concur with the expressions below. District and subdistrict offices seem not clear on their supply chain roles towards facilities. One participant said the following:

“Because I'm not doing these- things supply chain management - I'm just ensuring and facilitating. With the maintenance part of infrastructure, we've got the Artisan Superintendent and the maintenance component. The artisan superintendent liaises with the district engineer and the provincial one. But it is said, we are supporting facilities and yet we end up not supporting them. The district office says they are the ones who are in charge of the clinics. The whole work lies with us at the end of the day with no resources ...so are we supporting?" - subdistrict actor contextual mapping.

The province confirmed the existence of buckpassing with regards to supply chain and maintenance of facilities.

"Buck passing between the provincial office and the district offices first and foremost when you get into the district offices. They tell you about supply chain, problems at head office thats what they always complain about." - provincial actor round 1.

SUPPLY CHAIN CHALLENGES AFFECTING STAFF MORALE

Other actors explained how these supply chain challenges are inturn impacting on staff morale as revealed below;
"Such supply chain challnges happen a lot and maybe you will tell me, no this is not really care related but it defi- nitely impacts on the morale of the staff, on how we per- form. If there is no light bulb here I can't, maybe, write my report, and yet that kind of work (reports) goes into the care.If we don't have paracetamol, such things, sitting and waiting for things to happen, there is no panadol at the moment, you see, but we do not see such shortages in the private sector." - subdistrict actor round 2 .

SUPPLY CHAIN CHALLENGES AFFECTING ATTITUDE TOWARDS NATIONAL CORE STANDARD ASSESSMENT

Actors highlighted how contradictory and demotivating national core standards were as they were assessed on factors that were beyond their control and jurisdiction. Below is what was said:

"We fail on the National Core Standards because of that. When they do an audit they say, Where's your janitor's trolley? Okay, you don't have it, you have failed. Where is your pedal bin? Sorry, you've failed." So, when we score these low figures it is not always because of our performance. I am not saying we are perfect or we are performing at a very high level; it is going to take a lot of time, a lot of manpower to perform at that level, that NHI wants us to perform at. But I'm saying the things that can assist us to reach that level; those are the things that we need to be put in place. It makes you feel inadequate. You know this is what I'm supposed to be having in my clinic, you order and do not get it. Whe they come to audit you are viewed as not performing at the level because of lack of equipment, or supplies or whatever the case may be." - facility actor round 1.

"But still with the issue of equipment, whatever we do request with the NSI's (Non-Stock Item) it is very rare that we get the equipment. The basic things like if you can ask, we don't have even the suggestion box. The suggestion box that we have is just a box, not the prescribed steel one you know. When the national people come (auditors), they want to see the steel one, we don't have that one- such basic things despite ordering. It is damn irritating I am telling you." - facility actor round 1 .

*"They will tick, tick, you haven't got this, and that... Yes, you are then portrayed as a bad manager." -*facility actor round 1.

"Not yet, we don't even have a defibrillator but that is a requirement of the current national core standards. We do 


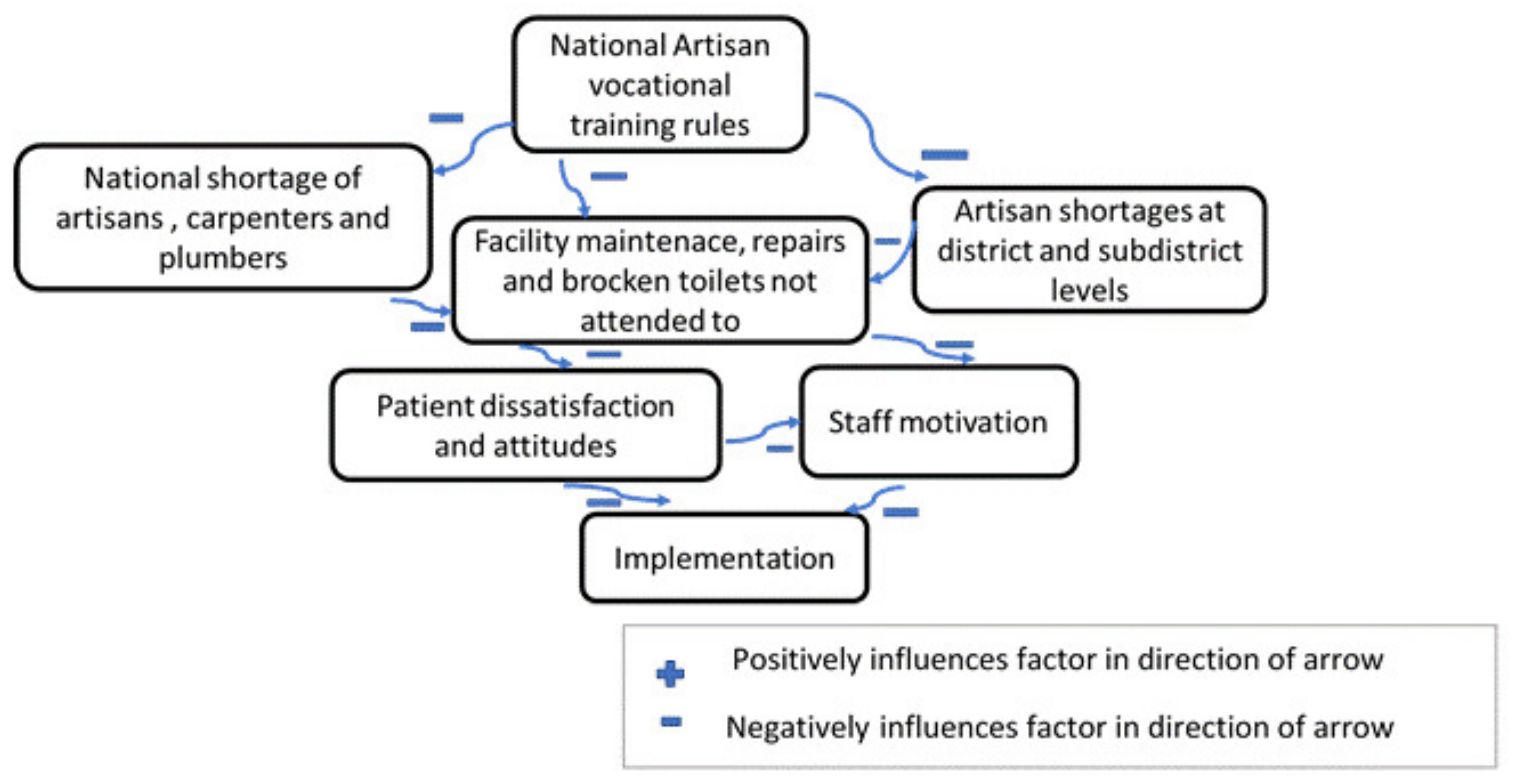

Figure 3. Extraneous factors bringing about a policy-practice gap.

not have the basic equipment. They tick us as zero." - facility actor round 2 .

NATIONAL VOCATIONAL TRAINING OF ARTISANS, VACANT ARTISAN POSTS AND MAINTENANCE ISSUES ORIGINATING OUTSIDE THE HEALTH SYSTEM

Actors at sub-district level, leadership responsible for supporting facilities, were aware of the supply chain challenges and pointed at the root causes of supply chain and maintenance woes as follows:

"But I must tell you that artisans are very hard to recruit. Electricians, plumbers, painters. They are very hard to recruit. The country needs to produce more. No, they are not producing them fast enough. Remember there used to be a process in the country where a youngster that does not want to go to university can...become an artisan? And that was stopped. Now they are trying to start it up again. So that is very important. We need qualified electricians' smiths etc. And you cannot find these people. They are very hard to recruit and then to retain." - subdistrict actor round 2

One provincial actor also confirmed the phenomenon as revealed below:

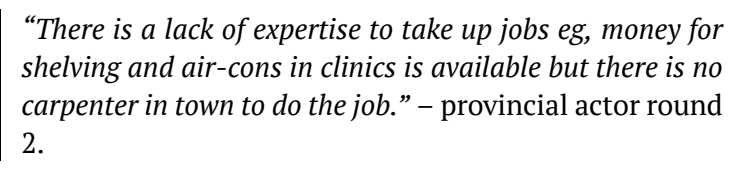

See Figure 3 below for some of the relationships and connections alluded to by participants.

\section{LINK BETWEEN RESOURCE CHALLENGES, PATIENT EXPECTATIONS AND PATIENT STAFF ATTITUDES}

The announcement of NHI brought hope to many South Africans who have associated NHI with private care standards now to be provided for by public institutions e.g cleanliness and reduced waiting times. There is currently a mismatch of high patient expectations created by the marketing of NHI in the media, and the conditions and resources on the ground that have not been fully upgraded to meet the advertised standards. Patients are then disillusioned when they attend a clinic or hospital, only to find a facility dirty or spend 3 to 4 hours in a queue due to staff shortages hence patient staff tensions. Some senior actors on the ground, at sub district level confirmed that nurses are being squeezed by supervisors from above and patients below as revealed here.

LINK BETWEEN STAFF SHORTAGES AND PATIENT ATTITUDES

\begin{abstract}
"One patient takes one nurse at least one hour. Right? And now you expect her to see ${ }^{34}$. She has only got 8 hours in a day so how is she going to do justice to her task?" - subdistrict actor round 2.

"It's the waiting period. Patients end up waiting for a long time and they end up complaining and we understand. They can see us busy, although we explain to them but it doesn't help. We can always say we are short today there are people on leave, some people go for workshops and then there is sick leave. It's affecting the patients, even the children will start crying because they have been in the queue for so long, and, you know, some of them are hungry. Even pregnant ladies, they need to go and eat and rest. You find them standing up because sitting for long too is uncomfortable, and they will walk around because they have been sitting too long. It's affecting the patients big time because although we have got waiting times of 3-4 hours, they end up waiting much longer due to shortage of staff." - facility actor round 2 .
\end{abstract}

LINK BETWEEN STAFF BURNOUT AND PATIENT ATTITUDES

Some actors suggested a possible relationship between staff burn out and patient attitudes as follows:

Maybe it's because we've also got a negative attitude, I don't know. Maybe they are feeling it from us, I don't 
know. But most of them, especially regarding my experience in this clinic, lodge complaints from time to time, I don't know. Some of the complaints are even lies. I don't know.... it's also hard to know, like you know patients are frustrated with different things. They can be frustrated with the queues; their own sickness their own problems, their own issues. I also think another thing; we as nurses also need to be attended to. Maybe we need some form of counselling at one stage or another. But we are really feeling burnt out. You know I can even tell you that sometimes we don't even get time to go for medical check-ups ourselves. At the moment I think it's because of the problem with burnt out syndrome. Hey, sometimes, you can feel and see other staff members becoming very aggressive towards each other, yeah." - facility actor round 1.

\section{LINK BETWEEN PATIENT-STAFF ATTITUDES AND STAFF MOTIVATION}

Most actors revealed how patients are creating a wedge between frontline actors and their supervisors by reporting what they said were untruths as follows:

"Recently, a patient came here. That patient had a problem waiting so at first, she went straight to the district hospital (name with held for anonymity reasons), they asked her to wait in the queue, then she left. She came here, she was asked to wait in the queue and she left again. She reported us to the District and said she didn't get help at our facility but she didn't report the district hospital. I don't know, maybe she did. We got reported that we chased her. You know she came with a card from the other facility where she was asked to wait too and never did. She came here, we told her the same story that she has to join the queue but she was in a hurry. And then she went, I don't know where she went from here. In a letter she says she went to another facility now, a third one now, where she got help. She said she got help from there with no hustle, she said. We get demotivated sometimes, because sometimes most of the complaints are not true. It's not the exact reflection of what happened. You know, as I say, the ones that don't sort it out here, they just go and say something terrible that we get shocked when we get a letter or the Public Relations Officer (PRO) phones and says someone is saying this. Someone who has been here, did not raise a complaint with us, only to find out its that person you assisted with a smile and they pretended happy themselves. That's where you get a shock that this person was here and she didn't show any signs of unhappiness, the next thing they go and report or maybe they'll report about the toilet or maybe they'll report about the waiting times but they were here, they got help, they didn't complain they went away as if everything was okay and that's where it just hurts eish, what can we do At least if they could complain here, we perhaps will be able to remember the person. Next thing you get a letter of complaint. That is not nice." - facility actor round 2 .

Other actors revealed how patients even threaten them when they wait too long as revealed below:

“Well, for example, the community as you see, they don't understand when they have to wait for a long time. Sometimes they have to wait for the staff to come back from lunch. Well, we do have people who have attitudes, sometimes they do threaten us." - facility actor round 2 .

\section{PATIENTS DEMANDING CARE}

Patients were reported to not only threaten staff but also made unrealistic demands, asking nurses to respond to these, irrespective of guidelines or protocol as follows:

"There are antibiotic protocols, where we are not allowed to give patients that are complaining of flu-like systems, antibiotics. I had this rude man that came to me. I assessed him and checked his chest. His chest was clear. He is a smoker. He says he wants an antibiotic. I said Sir, I cannot give you antibiotics based on what you are telling me. On my clinical assessment, you do not qualify for antibiotics. I can give you something for your runny nose and something for pain, but you need bedrest. And that is the protocol. He swore at me. I called the operational manager (OM) to speak to him. The OM spoke to him. He came back to my room after chatting to OM and said to me "I will show you and I will show this clinic". That is a personal threat on my life. I wrote a statement, but nothing has been done. What protection do I have as a nurse? I am being verbally abused but dare the patient complain, the nurse is taken up. What about the Nurses? You know what I am saying?" - facility actor round 2 .

Some actors suspected that the rise in complaints were being driven by an opportunistic attitude from patients as follows:

"There might be some other indicators like the caesarean section rate which is going up. So there also have been some litigation cases related to maternity which seems to be going up, also I don't know...I don't think that it's really the care which is going down. I think its people becoming more demanding, more aggressive, more knowledgeable to say we can sue the hospital in this case and this case and that has made the number of litigations go up, but in terms of care itself, I think there is some improvement. No, I don't think litigations are related to poor care, I don't think so because the number of adverse events has to increase to match the number of the litigations going up, what I think is that patients have become more aware of what they can do if they are not satisfied with the care they are being provided." - subdistrict actor round 2 .

LINK BETWEEN UNRESOLVED CHALLENGES, BUCKPASSING AND HIGH STAFF TURNOVER

Some actors even expressed resentment at their operational managers for the unresolved challenges despite these clearly being beyond the managers control, further creating local staff tensions as follows:

"There is a lot of personal issues going on with the Manager and the staff. They...well I can speak freely here?... They feel that he is not a good Manager in terms of everything because they feel he is not working as a team member. They also feel that he does not show initiative. He does not have the skills that are needed to be a Manager. So, it is a big issue in the clinic. I mentioned the cleanliness of the clinic. That needs to improve because I am busy with infection control and I am not happy with the standards. I mentioned the cleaner, the environment, the infrastructure. So, there has been a complaint about the clinic, the infrastructure for a long time and no-one is addressing it. They keep on shifting it to the municipality to $\mathrm{DOH}$ and DOH to municipality." - facility actor round 2. 
"The way things are going; staff are just wanting to leave and you wonder why they resign and leave $\mathrm{DOH}$. Go on an interview...they do not do exit interviews at $\mathrm{DOH}$. Ask them to do exit interviews and you are going to find out the reason why the staff are unhappy. Not because of their pensions. It is because they are burnt out and they are tired and they are fed up because things have not changed in the last 10 years, problems are never solved." - facility actor road round 2 .

LINK BETWEEN EMPLOYEE PERFORMANCE, MANAGEMENT AND DEVELOPMENT SYSTEM (EPMDS) AND MOTIVATION

The formal employee performance management development system that was introduced by $\mathrm{DOH}$ to instil motivation and reward performance was reported as a waste of time by many. Provincial, district, subdistrict and facility views from contextual to round two agree on the matter as revealed below:

"With the performance management systems, we are using the performance management system basically for giving you one per cent increase or whatever. The managers reward- not the primary purpose of improving the systems." - provincial actor round 1.

"That thing (EPMDS) must just be stopped. Because, you can see that I'm supposed to give a one, can you really just give that person a one? There are no 4's and 5's anymore. So just give 3 as an average. Useless thing, just wasting our money and time, must just give that one percent to everybody." - facility actor round 1 .

"Yes, it, it's a useful exercise if it's done correctly, but with our department even if you can praise somebody and you give her fours or fives, you are certain that she is doing well, there is no reward for that. So, at times, you just feel tired to do that, you just put everybody as average because it's not going to be considered. Instead, it's more work for you because you need to motivate for this, bring pictures, write lots and lots of papers, stating why you are saying she, she has gone an extra mile. So, it's not a fruitful exercise." - facility actor round 1.

"You know. At the end of the quarter it is a bit of a dicey issue with staff because they believe that initiative is not being recognised because what they do is, they score you on how you achieve your key result areas (KRAs) and if you achieve a score of 4 or 5 you are supposed to get like an incentive bonus- performance bonus and the department says there is no money. So, there is no money for that so whether you like it or not you will get a 3. Everybody gets 3. From me to the most junior clerk. We all get 3s." - subdistrict actor round 2.

"No, performance is not measured. It's a waste of time with these EPMDS. Waste of time, waste of money, waste of everything. No, it doesn't measure anything. Because even if I'm a person who works harder than others, but the marks are the same, for everyone. No, it's a waste." - facility actor round 2 .

\section{OVERALL MOTIVATION}

During round two, most actors revealed how their overall motivation was being affected by the multiple unresolved challenges (staff shortage, infrastructure, equipment, supply chain, lack of support, patient attitudes etc) as revealed below;
"None of us want to wake up in the morning and come to work. It is just that we are forced to come to work because we know we have to be here. We love...I am passionate about my job, but I cannot be passionate all the time when I am faced with these issues. I drag my feet to work. Because I have to be here." - facility actor round 2.

Managers at subdistrict and facility levels acknowledged these multiple unresolved challenges actors face daily and felt limited in what they could do to keep staff motivated as revealed below:

"Because you know the staff get so bogged down with the challenges that we're facing...And so and then you know we just try to pep them up with little open days and nurses' day functions and sports days and things like that, but then also those things you know, it is you taking them out of the ward to do that. We are taking them out of the wards so while they are having a juice and a sandwich, there is another person that is getting stressed because they see double amounts of patients. You know and it is demoralising because if you compare the cleanliness from last year this time, to this year you can see the difference. Now already it will tell you in our next audit we are going to fail that and we are going to come down in that area, so it brings down the score for the whole facility and then it demoralises the staff because we try so hard and we still fail for reasons beyond us. You know, it is totally, totally beyond our control." - subdistrict actor round 2.

See Figure 4 below for some of the relationships and connections alluded to by participants.

\section{CIT TENET: INTERACTIONS - PHC SUPERVISION}

The PHC supervisor is supposed to be the bridge between facility and district, the first one to turn to when facilities have challenges affecting service provision or policy implementation. The actors revealed that these interactions are erratic and when the visit takes place, PHC supervisors are unable to assist facilities solve their problems. The district was also aware of the PHC supervision challenges citing among others human resource shortages as follows;

"These PHC supervisors rush from clinic to clinic, hence
the application of the PHC supervision policy is not ad-
hered to, because they have more than five units to super-
vise. They supervise a lot of clinics." - district actor round
1.

\section{STAFF SHORTAGES AT DISTRICT LEVEL AND SUPERVISION}

Supervisors at district level themselves expressed how stretched they were with too many facilities, calling for attention as follows:

“.... unfortunately, it is just difficult for us to go back now and see if whatever we told them to do is being implemented ... Yes, to such an extent that whenever you meet some of them (facility staff), they keep on saying "you promised, when are you coming back?" You know now, it is as if we left them like that ... Yes, and they are looking up to us to be their saviours. Yes, they think if these people (PHC supervisors) come, our things will be sorted out. They wish we could visit them every month. But we can't... 


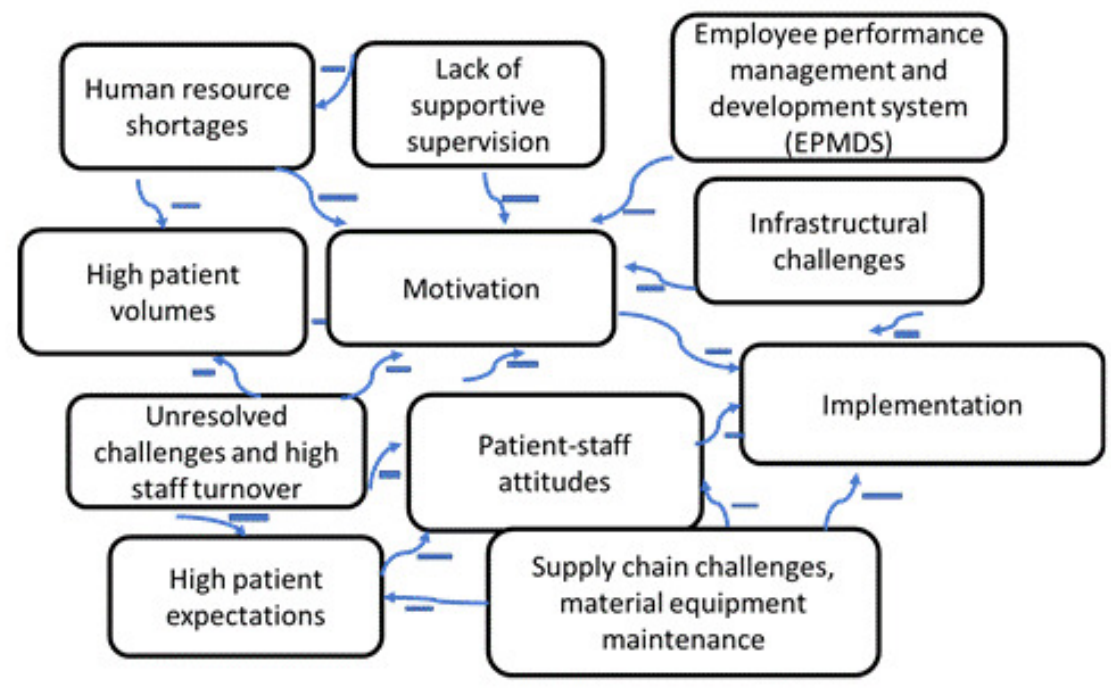

Positively influences factor in direction of arrow

- Negatively influences factor in direction of arrow

Figure 4. Summary diagram depicting factors affecting motivation, leading to negative policy implementation.

unfortunately we cannot cover all of them... because we cannot be in all the clinics." - district actor round 1.

\section{LACK OF SUPPORT FROM ABOVE AND NON-RESPONSIVE LEADERSHIP}

PHC supervision and support was revealed as demotivating at subdistrict and facility levels. Policing supervison was frequently cited by actors who were incensed by the fact that when they call for help, there is hardly a response-but when the Supervisors hear or find something wrong, they punish the staff, instead of being supportive and understanding, bearing in mind the conditions they are working under. These interactions were revealed as affecting motivation accompanied by feelings that the leadership does not care for them as revealed below:

"I report to the District Manager. Do we receive support visits from them? No... We only get a visit when there's something, which is not good enough. Yes, or when we're going to have the Minister coming or something or when the MEC is going to visit us. So no, it's not a support visit, as far as I'm concerned with supervision, if only they could highlight the problem while I am here, so that by the time we get there, at least they can ask me the question, "Why didn't you do it, because we had spoken about it?" Then that is different but if no one has ever highlighted a problem then it's a bit of a problem to all of a sudden descend on us. It is actually demotivating, because you only get spoken to when something is wrong. She only comes when there are assessments for National Core Standards or they're coming to audit or something similar. That's the only time she comes. Yes, and I'm not just talking about my immediate bosses. It is everybody. The bosses up there." - subdistrict actor round 1.

"Well, I think you know what, sometimes other PHC supervisors just come to find out your mistakes and all that, instead of you getting supported." - facility actor round
1.

POLICING SUPERVISION, PATIENT STAFF ATTITUDES AND STAFF MOTIVATION THROUGHOUT TO ROUND TWO

The sentiments on lack of support and policing supervision did not change through to second round of data collection. Of interest is what actors termed as victimization and lack of support when a patien lodges a complaint or a negative incident, related to challenges beyond the facilities, of which the supervisors are aware of as revealed below:

\footnotetext{
"PHC supervision, Oh, what answer do you want? Two days ago, and I still don't know how to deal with this, I was told the last time that the Province didn't approve of my motivations, my stats were too low, but it's not possible to work effectively like this. The programs are getting bigger, the queues are getting longer, and we're only two or three sisters. We cannot provide quality care. The sisters need leave, they need in-service training, they go on sick leave. I mean, so when one is gone what happens to the clinic? So those are the problems. The queues are getting longer, the patients are squealing, and then I also have problems when people in this community, find something wrong, sometimes they don't come and speak to us, because they know people in the district office. They SMS the district manager straight. Not hearing the proper story, they then come down on us." - facility actor round 2 .

"I have only seen our PHC supervisor when there are problems like she feels that the staff have attitudes or whatever and with her I find that you cannot communicate with her. It is like working with Hitler". Because it is her way or no way at all. Okay. We are all robots here. I'm being very honest. We all are burnt out because we come to work and work and work. There is no appreciation for the staff." facility actor round 2 .
} 


\section{TOO MANY INITIATIVES AND TOO MANY MEETINGS}

Many participants expressed how the number of meetings has increased with new NHI initiatives. Participants expressed how much they are failing to implement policies because of time. The district has its own meetings which the staff are summoned to as they are usually not told ahead of time. The department of health on the other hand, has chosen several partners to work with inorder to improve services. These too have their own data demands and meetings resulting in too many meetings, with no time for policy implementation. District, subdistrict and facility actors all alluded to this throughout.

"Besides the national ones, there are many other external actors that are helping with the health system-strengthening programme, that are helping with the leadership programmes in the district. Believe me there are a lot. There are a lot of partners here." - provincial actor round 1. "Lots of meetings ... and people always have expectations from you ... they always remember to come up with ... new interventions. And they are so quick to complain. If we haven't been to their meeting for instance, I got a report that I have not been to a hospital perinatal meeting, two meetings in succession. They don't care if I was somewhere else doing other things. The fact that I did not come, where was she? You know, people think that you are only attending to them when you have other duties too." - district actor round 1.

"Yes, it is a lot of metings, hey, I just went for a district meeting and then I had to come back and we had to have another meeting within the hospital where we had to sit and work on all those things that they gave us to work on, like partogram audits- important things. We have to work on them but it takes you away from your department and little time is left to implement all else." - subdistrict actor round 1 .

\section{LACK OF PLANNING AHEAD}

Many implementing actors expressed how no planning ahead could be an underlying problem leading to policypractice gaps. They expressed not only how often they were summoned to meetings which are many, duplicates, not coordinated and often leading to clashes as a major but, some actors identified inefficiencies, that not every one who attended the meeting had the knowledge of what needed to be done as follows:

"There are useful meetings but there are meetings that are duplicates and not useful and should be avoided. There are things that should be put together. The problem is that these things come from the top whether district or national they will say from now on you will have an $x$ committee and they don't even ask whether you can or not do it every week and within 24 hours if there is an incident-you must meet. There was another committee, clinical risk, where almost $95 \%$ of people in the meeting didn't know what a clinical risk was. We were asked to report on clinical risks, they started doing it on adverse cases which is different from risks. When speaking about risks, because risk is not something that has happened but something that you think will happen, so all those committees we are told we should have, sometimes do not understand what the committee entails and sometimes they duplicate things that have been done already. Its because it is the same people who are nominated for those meetings and these people have other clinical duties that they need to fulfil at the same time." - subdistrict actor round 1.

"Most of the times they (meetings) are unplanned. It's unplanned and that is very disturbing because I plan. When you leave home, you tell yourself, today I am going to do this and this and maybe tomorrow I need to go to the regional hospital (name withheld for anonymity) to make a follow up of this and this - all your plans are just jeopardised." - facility actor round 1 .

"That's what I'm saying, I don't have time to do my work, because I have to go to all these meetings." - subdistrict actor round 1.

"So, I think PHC supervisors have the same pressure as us. Some of the meetings, they are summoned too and cannot deny to attend, that is why they fail to visit us." - facility actor round 2 .

Some actors revealed that too many meetings are affecting implementation as they are left time deprived as revealed below;

"You know when we are undergoing our mentorship programme, we were told that we are going to do at least 20\% of clinical work ... yes, but because of the hectic schedules that we are having, it makes us not to be able to go and do our clinical work." - district actor round 1.

"The meetings are killing our time and then they leave us very little time to do our particular work." - subdistrict actor round 1.

The multiple meetings at the backdrop of staff shortages were in turn reported as affecting patients staff attitudes (tertiary) as revealed below:

"Meetings are affecting our work clearly, because the patients then have long waiting times, they have to wait for longer periods. Sometimes the patients become very rude, they don't understand they must come in and wait." - facility actor round 2

See Figure 5 below for some of the relationships and connections alluded to by participants.

\section{CIT TENET: POWER}

Power is defined as the capacity to direct the behaviour of others or control over people or activities. ${ }^{35}$ Actors at provincial level revealed different perceptions on the power the district management had. The district on the other hand said it had limited power to the extent of not even able to hire or fire staff. Facility actors concurred with this and revealed the lack of power at district and facility level as affecting policy implementation. Power was associated with financial delegations which seem to be still concentrated at the provincial and head offices. Processes eg, to employ staff were revealed as long and cumbersome so much so that patient care was inevitably affected, particularly when people retire, die, transfer or resign. PHC supervisors and the district expressed helplessness when facilities make requests eg, for more staff as they then in turn have to cascade the problem to province, only for the request to be accepted albeit with time lag or rejected. 


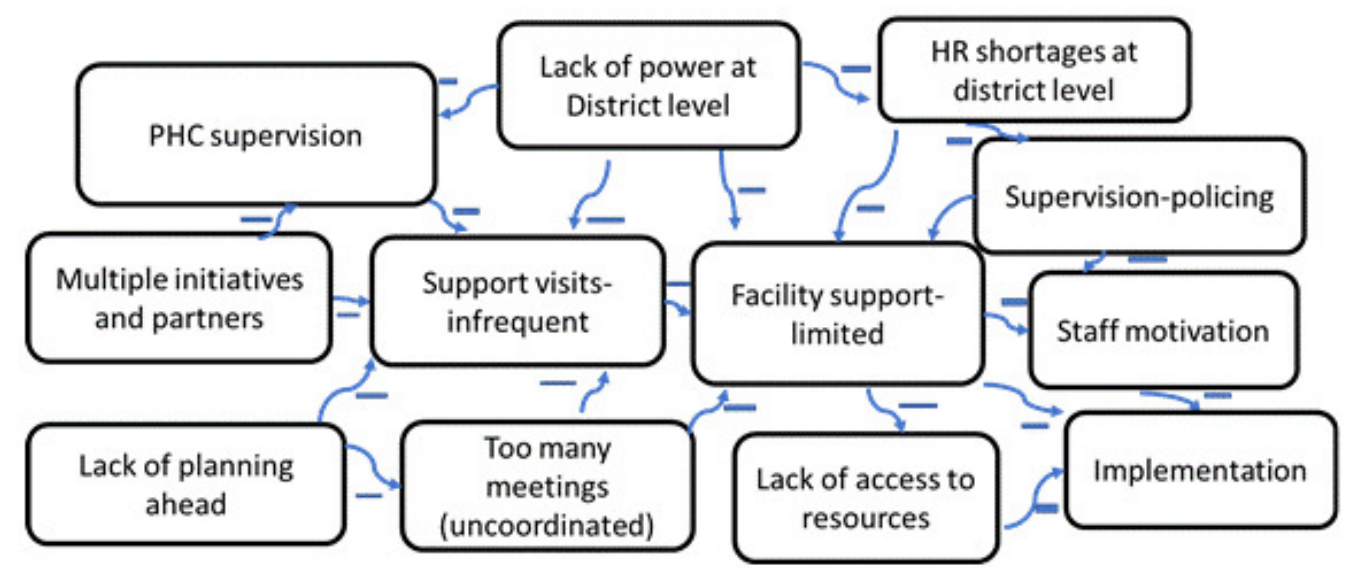

Positively influences factor in direction of arrow

- Negatively influences factor in direction of arrow

Figure 5. Actor interaction factors affecting policy-practice gap.

\section{DECISION MAKING SPACE}

Below are the different perceptions of power a district management team has, by provincial, district, sub-district and facility actors;

"They the district have enough decision-making space. Actually, our district (name withheld for anonymity reasons) is fortunate that it has got a fully decentralised but well-managed system. But of course, you'll have the limits in terms of finance, the budgets are to be regulated by the treasury thresholds that you can only procure up to this far. This is the threshold but all the managers below the district manager are his or her responsibility to employ, fire and hire as she deems fit. The district manager, is responsible for hiring all the managers that work with her, all the deputy managers at the district office. They all have the responsibility to take decisions in there based on the allocated budget and all the CEO's of these hospitals, report there, sign a performance agreement with him or her. They are reviewed by her. If there are any disciplinary processes, she has a responsibility to even discipline them. You allocate the whole budget here at the district office, and the budget is allocated per hospital facility. You have the district office that will remain with its own budget, administrative budget for running the district office and then we have the budget that is going to the different facilities. The $C E O$ is responsible for managing her own budget. They manage expenditure, the cash flows, and even submit motivation for movement of the budget within her facility, without necessarily removing accountability from the head of department. The head of department accounts to parliament for the expenditure here at province. Hence you have the chief financing officer (CFO) who is actually supervising and overseeing the equitable distribution of the funds as per needs but the district manager here is respon- sible for the expenditure here up to this level-district." provincial actor round 1 .

"There is a challenge, I think there is a misunderstanding of how the NHI pilot sites are funded, because there is a conditional grant. You need to know that a conditional grant has specifics, you can't use the conditional grant money to do whatever you want, because it is specified, what it is supposed to do. At the province level, they seem to think that they should not give you (district) more money because you have been given a conditional grant. Like I said earlier on, the recruitment of PHC teams and procurement of teams, it's not covered in the conditional grant, but there is a perception that we can't be given money because we have a conditional grant, but the conditional grant is specific for activities that it has to cover." - district actor contextual mapping.

Some posts, though created to further NHI initiatives had no power over resources and acted in an advisory role only:

"Well, I have got no space in terms of decision making, basically I'm in that NHI role, just as a project manager who has to work with the bare resources that are here, whatever I'm given by the province. I make recommendations to the province if there are any bottle necks to them like say, we need this here, that's all- more like an advisory role." provincial actor round 1 .

\section{TOP DOWN DIRECTIVES}

Most actors expressed they get directives from the top, without being involved, and that these directives are often unrealistic. 
"Even in the next business plan, that is what I was saying, the outcomes are determined nationally, so you can't put what you want." - district actor contextual mapping. "I will make an example, we are trying to argue for the issue of PHC teams, the family teams, their conditions of service, we are losing them because their conditions of service are not conducive. We were proposing that from the conditional grant, we be allowed to have a small trailer, it's a small office trailer that we can pull along, so that when we get to a household, we are able to interview people in a comfortable environment, and we are able to capture all information there-and they said we can't do that, but we are saying it's strengthening the PHC, which is a pillar for NHI, one of the pillars for NHI, but then they say you can't, you can't buy those trailers." - district actor contextual mapping.

Some actors pointed how top down directives associated with limited financial delegations are directly affecting service delivery as follows:

"Now with the state that our SCM and head office is in right now that is my biggest stumbling block. The contracts are not being renewed on time. Our outsourced services are letting us down very badly but they have come to an end like our catering contract. It has come to an end. Why is it still here? Why has it now gone onto an extension? despite all the negative complaints...The cleaning contract. Why is that company still in place? That is like a R400 000.00 delegation. Mine is R250 000.00 so therefore I cannot choose my own company. Head Office chooses the company that is cleaning my facility and then how is it that I get given a company that has no mops, no cleaning material, no trolleys. No equipment to clean. No infrastructure themselves." - subdistrict actor round 2.

\section{UNREALISTIC TARGETS}

Most participants revealed how unrealistic the targets set by those at the top are. They then fail to comply due to their unrealistic nature and lack of insight of those who set them. Participants revealed the following;

Our occupancy target is $60 \%$. We hardly reach 60 , we are sitting at 51-55...the average is 55\%. So that causes confusion also? Why are we sitting there-because even at a provincial level we are accused for failing to reach targets, because our beds are not full? When I'm giving narrations in our quarterly report, I always say, it means our primary care clinics are working well. Why do you want patients to be sick again? Our seniors are failing to understand that." - subdistrict actor round 1.

“Who sets the targets? Oh, I don't know, don't ask me I don't know. All I know is they are always talking about the targets". That is the goal of us being here is to make these targets." - facility actor round 1 .

Other actors expressed how those seniors who set targets for them fail to provide support to meet those targets when asked as revealed below:

"Let's say if you've got a target that you are not meeting, they'll tell you that you must upgrade this program, when I'm asking for support, no support. There's no support, I can say that so how can I reach those targets." - facility actor round 1 .
Others expressed how the set targets infringe on respect for patients`autonomy to seek care as follows:

"Targets...I cannot go and fetch you from your house and
force you to come to the clinic. It is your decision." - facil-
ity actor round 2.

UNREALISTIC DATA DEMANDS

All participants expressed additional unrealistic data demands with multiple registers, leaving little time for patient care. Data challenges were mentioned as one of the many unrealistic demands made from the top. Most participants expressed that there were too many registers and forms to fill, that at the end of the day, they seem forced to nurse either registers or patients. One participant revealed the following:

"The ANC register, you will write from here to the capital city and each and every programme comes and says but my column is not complete ... my column is not this... then you think to yourself, you just end up looking at it and thinking, do you think really and truly I am worried about your column? I am not worried about your column; I am worried about the mother and the baby and the healthy baby that is going to come out." - facility actor round 1 .

"Then you have got to take time with the recording so you make sure that all requirements are met so we do not have any litigations. After that we spend little time with the patient -you know what I am saying." - facility actor round 2.

\section{CONDITIONAL GRANT AND BUDGETS}

Each of the eleven NHI pilot sites in South Africa received a conditional grant which was to be spent on service delivery interventions being implemented under the banner NHI piloting. ${ }^{36}$ Many district managers indicated they were not involved and did not know what the NHI infrastructure money was spent on. ${ }^{36}$

"From the conditional grant [what is not spent], at the end of the year it goes back, which is a waste, because there are real needs, but they want us to spend it in a certain way and we haven't been doing that. Probably that's our own fault. There are issues that are big to dissect. Sometimes the tender processes take time to get service providers and so on." - district actor round 2.

Other actors reportedly did not get any allocation of the NHI grant in 2015 as revealed below:

“We didn't even get money this year in this hospital [no allocation of the NHI grant]" - subdistrict actor round 2.

\section{FINANCIAL DELEGATIONS}

"The only challenge that we say, we always say is in relation to the financial delegations, because the financial delegations, both at an institutional and a district level, are exactly the same. So if there is a challenge, in a hospital, there isn't a thing that we can do at a district level to assist, we all have R30 000 for things that we get quotes for and anything about above R30 000 has to go to a tender, up to R200 000 and you know that the process is long and then anything above $R 200000$ has to go to province and 
that is where the bottle neck is. I think its because of capacity issues that they have at head office level, to such an extent that there have been items that we wanted to procure for NHI that have been there for approval for more than two years and they have not been able to move at a provincial level-so there is a challenge in terms of that." district actor contextual mapping.

"You know when it comes to the budget, you can say you have influence but then it depends on what the priorities are, but we do not have influence on the budget. I must say because yes, we do submit our requirements you knowthe plans, but sometimes we do not get what we have requested. Our only influence is just to submit our business plan, that is all." - facility actor round 1 .

Actors at facility levels through out expressed that they are not involved in decision making with regards to budgets allocated to their facilities. Instead PHC supervisors sit in those meetings held at district level, where decisions are made on behalf of the facilities as revealed below:

\begin{abstract}
"Whereas with us, we are not involved in those meetings so we don't know. I'll give you an example. Last year, at the beginning of the year, well, at the end of 2012, I submitted a business plan, saying exactly what I needed for my clinic. I was told then that there was no money available. The financial year starts in April, so I was told that in April I've got to fill in all my Non-Stock Item (NSIs) forms, to say, according to your Business Plan, this is what I have asked for. And I did all that and, up until today, I haven't received anything from them, so my point is, If you are going to keep on telling me, I don't have any money to buy these things for your clinic, why then am I wasting my time doing this (submitting business plans yearly)?" - facility actor round 1 .
\end{abstract}

DECISIONS MADE AT THE TOP DO NOT MATCH FACILITY PRIORITIES

Participants also revealed how those decisions made by people removed from the coal face lead to their own facility priorities not being addressed:

"Because at times iflet's say you have motivated for equipment, here we've got a challenge of privacy, we are short of curtains, we are supposed to do pap smears, but at the end of the day, they'll give you scales, they don't know your priorities, because you are not there when decisions are made, to emphasize this is the thing that I need most for now, this is exactly how I want it. So, they'll deliver... as they delivered the four watches (clocks) for the wall, we need them but its not a priority for this facility, we need curtains to do pap smears." - facility actor round 1.

\section{BUDGET ALLOCATIONS NOT CLEARLY COMMUNICATED TO FACILITIES}

The district actors acknowledged that clinic budgets are low but there seems to be a communication gap since the facility actors seem not aware of why the requests they submit are not honoured as revealed below:

"Yes, and also the budget which is being allocated to the clinic is too little to run the clinic for the whole year." district actor round 1.
LINK BETWEEN BUDGET RESTRICTIONS, TRAINING AND NURSE PERFORMANCE

The budget restrictions were also revealed to affect training and consequently nurse performance as revealed below:

\begin{abstract}
"Because we have to provide the person with the resources to work. You find that you recommend that maybe the staff be sent for a certain training, we are told there are no funds, you can't help that person. So, she will not perform up to an expected standard. At the same time, you can't penalize that person, because you didn't provide the relevant resources for her to perform well." - facility actor round 1 .
\end{abstract}

See Figure 6 for some of the relationships and connections alluded to by participants.

\section{INDUCTIVE THEMES}

In addition to the CIT core constructs, actors gave insights into other factors bringing about a policy -practice gap in their every day work.

\section{CHANGING EPIDEMIOLOGIC PROFILES-HIGH PATIENT VOLUMES}

Many actors revealed there were high patient volumes including a surge in non-communicable diseases (NCDs) that was not matched with human, material or infrastructural adjustments on the ground including new epidemics like violence:

"A surge of NCDs, yes. The problem is, I'm not gonna say it's just stable there is a little increase, but it's supposed to be more. The problem is that we don't have enough staff to do the vital signs, for each and every visit, for everybody who comes here. So many patients remain undiagnosed." - facility actor round 1.

"There is an increased number of patients with non-communicable diseases, you see. But you see we are not able to manage them the way they have to be managed, because like the diseases of the life style, where you do lot of the health education but the doctor has no time. Doctor has to see ${ }^{37}$ patients but he cannot spend half an hour on one person explaining you need to do all those things. It is just to see that blood is taken and diagnosis and treatment and move onto the next person." - subdistrict actor round 1.

The unplanned for high patient volumes, are inturn affecting training plans and dictating services to be provided bringing in a policy-practice gap.

“Yes, we've got our internal training plans, since we've got the PHC trainer, but unfortunately, we tend not to follow the plan as is because of the busyness of the clinic, currently that trainer is working on night duty due to shortages." - facility actor round 1 .

"I have drawn up a training plan, yes, but unfortunately we don't stick to it because of the circumstances of the clinic. Short staffed and too many patients." - facility actor round 2 . 


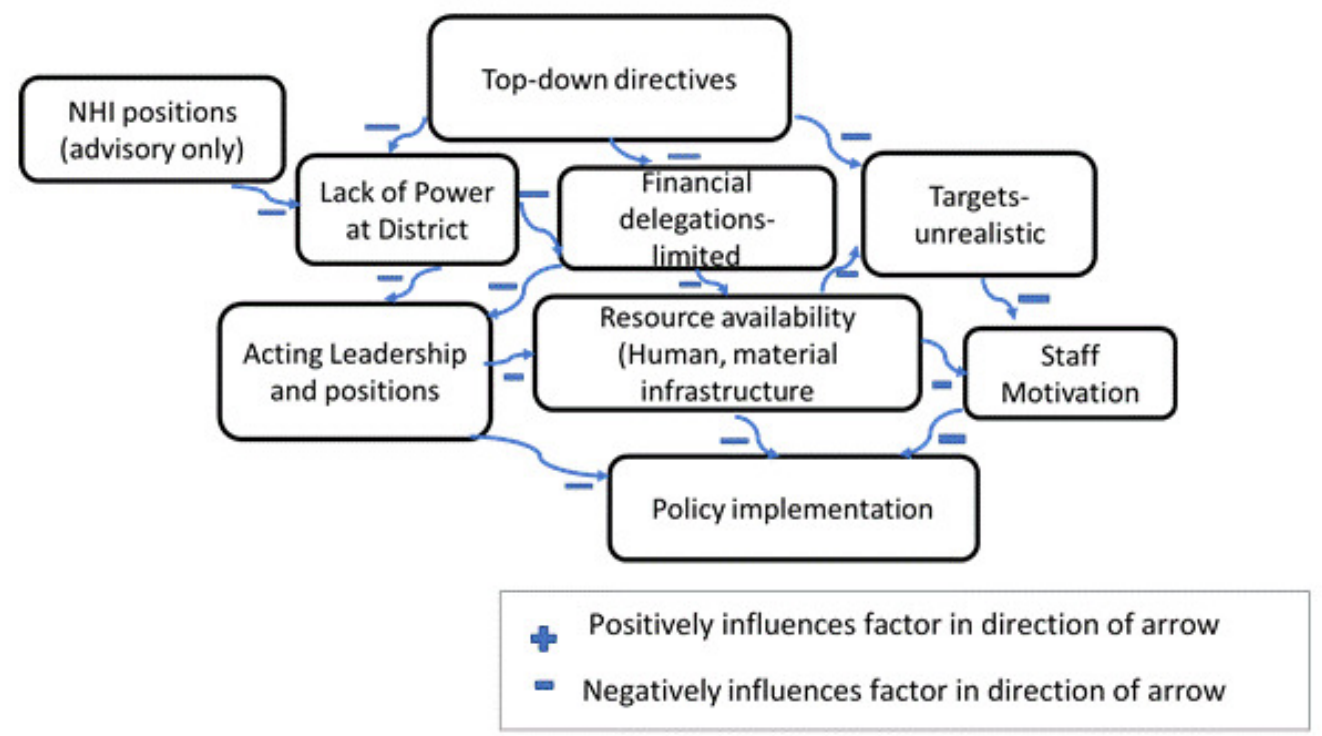

Figure 6. Power related factors associated with policy-practice gaps.

\section{TRANSITION STATES NOT PLANNED FOR}

Some facilities like hospitals that had once a regional status, were downgraded to district hopitals. Transitions take time. The establishment of a facility is prescribed from the top. Many actors at the subdistrict level revealed frustration as there is no contact person in case of transition challenges. They sought audience with superiors, to make them aware of the needs on the ground, that dictated keeping some services that had officially been declared as not relevant at this level, available as follows:

"The district package of service does not require an anaesthetist because anyone can do local anaesthetic for a Caesar. For that kind of surgery. But because we have an influx of all of these cases, we still have anaesthetists. It is dictated by the public need. Now that needs to be brought into the minds of our principals. I have said that at meetings. They say we have an identity crisis because we are doing the work of others but they do not realise that when you are on the ground, you know what actually transpires. Yes. Top to bottom prescriptions. They have prescribed, they say you may not do open reductions and fixations and that because it is not in the district package of service. But every second patient that comes out of a car crash needs that." - subdistrict actor round 2.

\section{IDEAL REPORTING}

Left to deal with challenges on their own, participants revealed how they are forced to make decisions that work in their context. Many actors revealed how they then report according to expectations just to keep the supervisors off their back. This has led to what we termed ideal reporting -a response from frontline actors in reponse to policing supervision. Ideal reporting was alluded to by actors at provincial level. Facility level actors shared how that comes about below:

\begin{abstract}
"It's typical of the leadership gaps. Somewhere in the system, at whatever level... I went in to another facility like I've been running around recently. I went there to check my blood sugar and to get my chronic medication. They did not actually have the machine to check my blood sugar. So, that's what you find hence it talks to all of us. Where I'm sitting in the health system, there are managers that are supposed to be monitoring that. Yet I am getting all these glossy reports that are saying everything is fine like this. When you go down there you discover something else." - provincial actor round 1 .

"Quality improvement ... according to them, we should be having a quality improvement plan, but no, because the quality improvement plan needs the person to be there ... the human person to be there, who will be ensuring that these things are implemented. They ignore us. They say oh the nurses keep on complaining. So, you end up not reporting some of the other things because they would say this nurse is the problem. So, we tell them what they want to hear." - facility actor round 1 .

"There are even departments that do not exist according to head office but on the ground, we have to keep them open, because they are important departments." - subdistrict actor round 1.
\end{abstract}

\section{SYSTEMS THINKING CHALLENGES}

Participants revealed how a lack of systems thinking is leading to discrepancies between practice and policy. This lack of systems thinking was revealed in different forms. Other actors expressed how a new boiler had burnt due to lack of maintenance. Many shared the computer example. During round one computers that were meant for clinics were found in a board room at subdistrict level. The reason being computers were brought to clinics without forecasting security issues and as a result some clinics were burgled into and the rest were returned to subdistrict for safe keeping until clinics had security guards. Actors at subdistrict and facility level shared similar concerns during both rounds: 
"Yes, last month, as I'm responsible for all the computers, I received a phone call from one of our colleagues here saying there are computers that are coming, so you must organise the space for them, because this NHI thing, they need every consulting room to have a computer, even the clinics. Although they had installed the computers in the clinics, I had to go and fetch all those computers, they are sitting here now, in our boardroom. Yes, they received... maybe each clinic received about 13 to 15 computers, for each consulting room, so we had to go and fetch all those computers because we don't have security. So, we said no, it's risky to have to have the computers there while we are still organising the security. We said these computers will be stolen, so we took a decision to go and fetch all of them and keep them here." - subdistrict actor round 1.

There is no security, so we don't have protection. We are protected by God. They even brought the computers here and then I asked them, how dare you bring the computers? Who is going to be held accountable ... I mean I am not going to write a statement and say these computers were brought here and then if they go missing, don't blame me. Because you know that nobody is here at night and if somebody comes and takes them, I will stand on one side and let the person take the computers, there is nothing I can do. Difficult is not the word. It is very frustrating." facility actor round 1.

During the next round two nurses expressed how the security issue had been solved but that none of them had been trained to use the computers:

"So here we are wasting money. Computers are here, they are not installed, not in use, no the staff are not even computer ready (no training)." - facility actor round 2 .

"So, now each and every room has a computer. The computers are sitting there, because no one went for training." - facility actor round 2.

The lack of systems thinking was also revealed in other areas, for example in the companies that were contracted for services at provincial level but sent to hospitals eg, catering and cleaning:

"You see you can have a clean facility but the facility could not be following infection control principles, because in infection control you know that you must clean with that kind of strength, that colour mop and stuff like that. So, what happens with the private companies because they do all their HR issues, training, everything they just say okay I want to clean now? This is probably not a clinical person that owns the company so he knows how he mops his house and that's all. So that is what he expects to be done here and when they come in here, we say okay, infection control protocols demands that you must have three mops, you must use this colour here, this colour there and that makes no sense to them.You will find one will say okay my blue mop broke so never mind, I will just use the toilet mop in the kitchen, it does not matter you know. Because at home we do that, so why should it be different here you know, although there is this whole awareness of $H I V, T B$ and things like that they do not take responsibility for taking care of their own health.so you will find them wringing the mops out. You will find them walking around without gloves, without masks. So, they have very little understanding of infection control principles. If we say to them the curtains in the ward need to be washed on a weekly basis, they ask why? At home I wash them once in three months, so why should I do it weekly here?" - subdistrict actor round 2.

Other actors revealed the lack of systems thinking in how the new epidemiological profiles have not been planned for as follows:
"In those years we were, oh so well organised. We enjoyed working here. It was so beautiful to work here. You know, things were in place, but the other thing is, we didn't have so many patients. You know what, as the patient workload increased, we should have had some system im- provements, but everything just stayed like that, instead of improving our systems, right? We were getting more pa- tients, so our systems were supposed to be improved from the top to bottom, they remained like that. When the load started coming then the bottom started collapsing and it's collapsing as we speak." - subdistrict actor round 2.

\section{AUDIT DRIVEN COMPLIANCE-UNINTENDED CONSEQUENCES OF POLICY}

Policy implementation was revealed not to be linear and some unintended consequences of policy were reported. Of interest is the emergence of audit driven compliance with the national core standards. The assessment of the national core standards was meant to improve the standards of care and services in the facilities, by making sure they move towards accreditation. The process however, was seen by staff as punitive when their facilty failed for not having equipment or infrastructure beyond their control. That spurned an audit driven compliance rush, where actors ran around borrowing equipment and material from other facilities, for the sole purpose of passing the NCS assessment. Post assessment, borrowed equipment and material is returned to respective facilities and service delivery carries on as before. Participants said the following:
"No colleagues and other OMs from other clinics are very helpful. Yes, and if only resources were within my power, then I would be ready for the audits, you know. Like I said, most of these things come from the supply chain. So, I went to theatre, I went to ICU, because I have connec- tions, and I said, guys, I am being audited tomorrow and my emergency trolley is empty. I am being audited tomor- row and I'm thinking, I need this and that. I don't want 100-percent, nobody gets 100-percent, but I don't want to get 40. Personality, contacts and connections help before audits." - facility actor round 1 .

Many actors also saw the national core standards assessment as a paper exercise or tick boxes as revealed below:

\footnotetext{
"National core standards are that thick document which has a lot of small boxes that must be completed (ticked)." - subdistrict actor round 1.

"It is here in this file. I know that it is available, but as I have got to consult patients, I just forget about the paperwork." - facility actor round 1 .

"I will be sincere; I don't think that it helps much because it's a paper driven process. So, you take these policies and you can tick compliant, non-compliant and so on. If they are not being implemented .... as most heads of clinical departments don't attend those meetings...it does not help." - subdistrict actor round 1.
} 
National core standards assessments include verfying the availability of policy documents in the unit. Pre-assessment actors revealed how they run around to find policies, not for staff to learn and follow, but simply for the purpose of passing as follows:

\begin{abstract}
"And if you don't have one (a policy) and you've never heard of it, when you go to them (PHC supervisors) they don't go out of their way to look for it or to help you look for it. Yes. There's a lot of things now, the OM does a lot of running around, looking for things, now we are going to get assessed again we start looking and running again." facility actor round 2 .
\end{abstract}

Tired of running around everytime, some actors resorted to the locking up of guidelines just to be audit ready making access if needed difficult as revealed below:

\begin{abstract}
"It is very difficult to work. Even say, my training guidelines, set protocols, policies. I can't leave them here; I have to lock them up. Who needs to use it? They have to sign for it, then I give them, then they give it back. I can't leave them out here, they are gone and come audit time I have to run again." - subdistrict actor round 2 .
\end{abstract}

\section{DISCONNECT BETWEEN THOSE WHO AWARD CONTRACTS AND THOSE HELD ACCOUNTABLE FOR SERVICE}

As explained earlier in the section of limited financial delegations, appointment of companies that provide cleaning and catering services is done at provincial level, since these services cost much higher than the R250 000 a CEO has delegations on. The challenge is the disconnect between the actors on the ground who get evaluated and those at the top who award these contracts but are not held accountable for facility cleanliness as revealed below:

\begin{abstract}
"Yes, we are getting complaints about bathrooms, toilets, everything. The appointment of service providers cleaning and catering is done at higher level province because the budget is higher than R250 000.00 but we still have to pay from our own budget. And if the service is not good, there is nothing that we can do. It is beyond us but we are evaluated on that. It's us who fail not those at the top who appointed the companies." - subdistrict actor round 2.

"The cleaning is out of my hands. It does make me angry but it is beyond my delegation. You expect that things should be put in place to not to frustrate you but unfortunately, they do frustrate. And then when the media queries come, I have got to answer. Yes, and that does frustrate me as a manager." - subdistrict actor round 2 .
\end{abstract}

\section{NON-RESPONSIVE LEADERSHIP}

Some actors revealed how supervisors seem oblivious to their infrastructural and supply chain challenges leading to infection control violations as nurses consult in non-conducive rooms with no hand basins as revealed below:

"Actually, they should condemn this clinic and then build a new one, because everything is wrong. There is a hole in the roof in one of the rooms in the ceiling. The Sister who is working there works without a wash basin which is a necessity. How does she wash her hands in-between patients? So, there is no infection control? And in the immunisation room there is no hand wash basin as well. How do you wash your hands in between patients, she sees ill patients? There is no way you can run into another person's room every minute to wash your hands. So, there is no infection control. I put that in my reports every month, but nothing has been done so how can this be an NHI pilot site?" - facility actor round 2 .

\section{BUREACRACY}

Some participants alluded to systemic issues that affect implementation as revealed below:

"What I'm trying to display here is that we still have these inhibiting policies. You see, in the public service, to get rid of this one official it takes two years in government. Just to finally get rid of dead wood. That obvious dead wood. It takes a lot of energy, a lot of documents for proof. Yes, getting the documents probably may not be the difficult part of it, but now managing these processes with all the leeways of appeals. All the leeways of appeals, all the different stages, and the energy that it consumes from a manager out of your core business? Managing one person and sacrificing the rest? The choice is clear." - provincial actor round 1 .

"So, government is over-regulated. You have all these red tapes that are affecting the whole of South Africa. Bargaining chambers for example to recruit a doctor. Any organisation will go to what you call these professional networks. You get a good CV there and invite the person for an interview, set up a panel. Here, I have to do a process three months long, just to get the adverts out. So, those are the systemic processes that are very difficult to actually work within, those are the major macro challenges. Then you also have what I would classify as micro challenges. There is the social silence, things that you cannot touch but things that are existing and persisting. In government, it's business as usual. My job is secure. People do not get fired. They are just transferred out." - provincial actor round 1.

See Figure 7 below for some of the relationships and connections alluded to by participants.

\section{DISCUSSION}

\section{PRIMARY, SECONDARY, TERTIARY AND EXTRANEOUS FACTORS BRINGING ABOUT POLICY-PRACTICE GAP}

In line with Bressers, ${ }^{23,25}$ our findings revealed that core constructs (deductive themes); Information, Motivation, Power, Resources and Interactions affect policy implementation at all levels. Also concurring with Bressers, ${ }^{23,25}$ we further found out that these constructs were interelated and interconnected, creating new dimensions of responses (inductive themes) that further widened the policy-practice chasm. In addition to the the core constructs of CIT (Information, Motivation, Power, Resources and Interactions) our research revealed changing epidemiological profiles, dysfuntional processes and systems (supply chain challenges, lack of supportive supervision, bureaucracy, disconnect between those who award contacts and those held accountable for service, too many initiatives and meetings, top down directives), human factors (perception, ideal reporting, buckpassing, patient staff attitudes, audit driven compliance), national vocational training regulations and an 


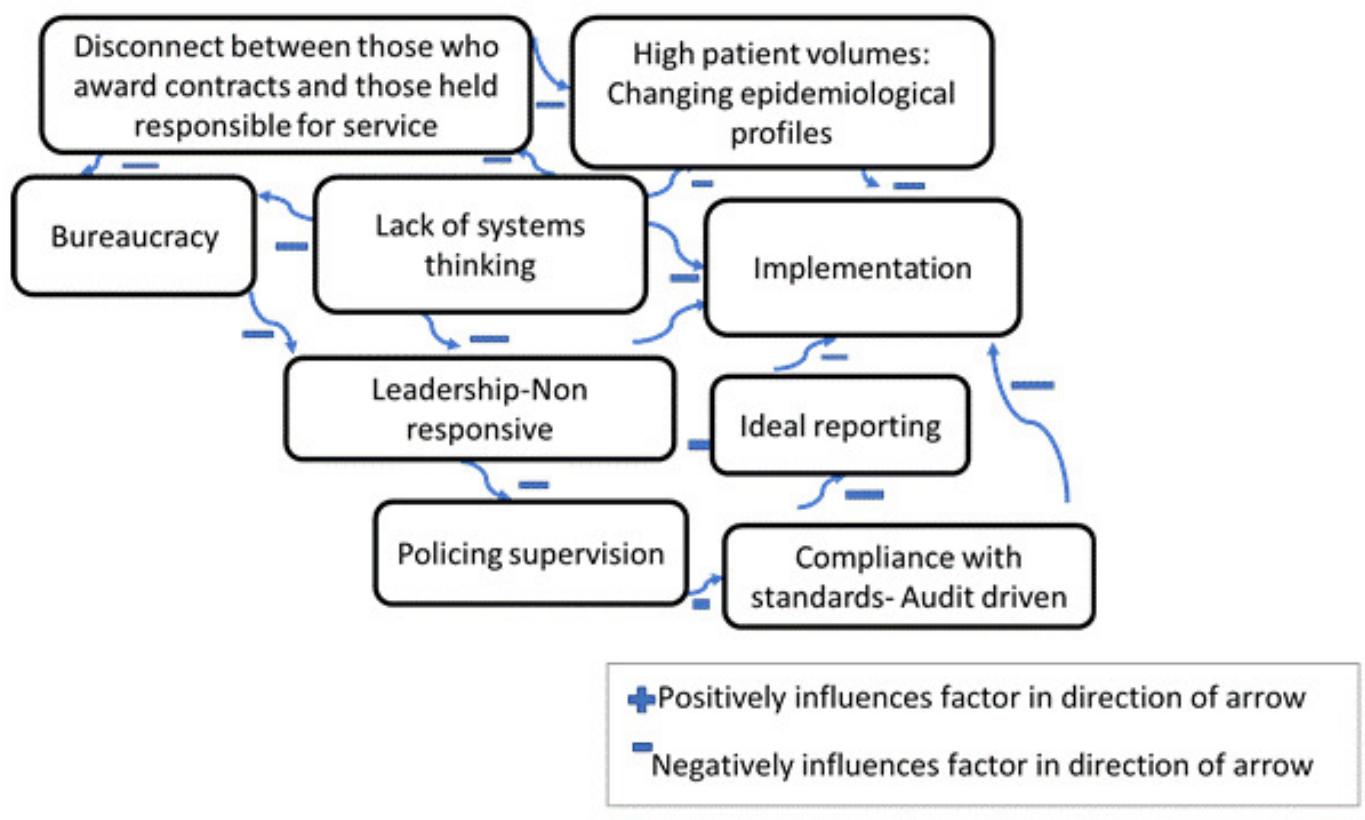

Figure 7. Inductive themes and some of the relationships affecting policy practice gap and some relationships among them.

Summary depiction of how policy-practice gaps come about (inductive and deductive themes).

overall lack of systems thinking as factors contributing to the policy practice gap in UHC policy implementation. See table 2 for summary of themes. To facilitate discussion and understanding, we categorised these factors into five groups namely primary, secondary, tertiary and extraneous factors and a lack of systems thinking.

\section{THEME 1: PRIMARY FACTORS - A DIRECT LACK OF A} CRITICAL COMPONENT FOR POLICY IMPLEMENTATION, TANGIBLE OR INTANGIBLE EG, INFORMATION. RESOURCES, MOTIVATION AND POWER

Our research revealed that primary factors; lack of information, motivation, power, human, material resource shortages, infrastructural challenges, the reality on the ground (context) are fuelling the policy-practice gap. In support of our findings Hardee et al (2012), identified resource mobilization challenges such as constrained budgets as affecting policy implementation. ${ }^{38}$ These findings are also in line with Weaver et al, who identified that implementers often lack human, organizational, technological or financial resources needed to achieve program objectives. ${ }^{39}$ Our findings further concur with Ranchod et al who revealed that the public health sector in South Africa faces financial constraints, low human-resourcing ratios and ageing infrastructure. ${ }^{27,40}$ Nurses from the province took to the streets in December 2018, complaining of one nurse having to take care of sixty patients, poor working conditions and shortages of human and material resources. ${ }^{41}$ Human resources for health are in short supply and these factors emerged as affecting staff motivation. If not addressed, these factors could compound the already dire human resources for health situation. ${ }^{27}$
Facility actors are cognisant of the reality or situation on the ground also known as context. Context is defined as anything external to a policy that may act as a barrier or facilitator to its implementation. According to Bowen and Zwi, context is defined as a setting in which policy is developed and implemented, consisting of political, social, historical and economic, epidemiological elements as well as health care system and service context. ${ }^{34,42}$ For the purpose of this paper we define context as including the above-mentioned elements as well as what actors described as the reality on the ground. Implementation often varies from context to context ${ }^{14}$ and for facilities, the most pressing challenges ranged from human resource shortages, infrastructural challenges, high patient volumes and supply chain processes. Capturing context is important as an intervention may have different effects in different contexts even when implementation is uniform. ${ }^{14} \mathrm{~A}$ policy might be relatively simple but its interaction with the context might be highly complex. ${ }^{14}$ Accordig to Bressers, context matters in policy implementation and it matters a lot. ${ }^{17}$ Facility actors would like superiors to take the individual facility contexts into account when planning and implementing policies, as the needs vary from facility to facility.

\section{INTERCONNECTEDNESS AND SYSTEMS THINKING}

The links between motivation, power, resources, information, interactions and context demonstrate the need for a systems thinking approach since policy implementation is a complex process. ${ }^{18}$ Our findings demonstrated the interconnectedness of Information, Motivation, Power, Resources and Interactions among others. ${ }^{42}$ Worthy noting is the onslaught on motivation, as each of the individual con- 
Table 2. Summary of emergent themes

\begin{tabular}{|c|c|c|}
\hline Theme & Category & Unit meaning \\
\hline \multirow{14}{*}{$\begin{array}{l}\text { Primary factors: A direct lack of a critical } \\
\text { component for policy implementation } \\
\text { tangible or intangible }\end{array}$} & \multirow[t]{3}{*}{ Information (policy) } & Top down directives \\
\hline & & $\begin{array}{l}\text { Seniors have more access to information that } \\
\text { juniors }\end{array}$ \\
\hline & & $\begin{array}{l}\text { Reality on the ground unknown by supervisors } \\
\text { and those at the top }\end{array}$ \\
\hline & \multirow[t]{2}{*}{ Motivation } & High intrinsic motivation \\
\hline & & $\begin{array}{l}\text { Demotivated by unresolved challenges staff, } \\
\text { material and infrastructural, lack of support, } \\
\text { supply chain challenges }\end{array}$ \\
\hline & \multirow[t]{2}{*}{ Power } & $\begin{array}{l}\text { District has no power to create posts, hire or fire } \\
\text { staff }\end{array}$ \\
\hline & & Facilities have no power to hire or fire staff \\
\hline & \multirow[t]{6}{*}{ Resources } & $\begin{array}{l}\text { Human resources shortages of nurses, data } \\
\text { capturers, cleaners and security }\end{array}$ \\
\hline & & Infrastructure, old delapidated buildings \\
\hline & & Limited space \\
\hline & & Hospital bed shortages \\
\hline & & New buidings not yet commissioned \\
\hline & & $\begin{array}{l}\text { Ownership and responsibility disputes between } \\
\text { government and municipality }\end{array}$ \\
\hline & $\begin{array}{l}\text { Situation on the ground } \\
\text { (context entailing all of } \\
\text { the above }\end{array}$ & $\begin{array}{l}\text { Material resources, shortages equipment, and } \\
\text { cleaning material }\end{array}$ \\
\hline \multirow[t]{13}{*}{ Secondary factors } & \multirow{3}{*}{$\begin{array}{l}\text { Budget and grants } \\
\text { systems }\end{array}$} & Budget not sufficient for clinics \\
\hline & & Limited Financial delegations \\
\hline & & $\begin{array}{l}\text { Disconnect between those who award contracts } \\
\text { and those held accountable for service }\end{array}$ \\
\hline & \multirow{4}{*}{$\begin{array}{l}\text { Communication } \\
\text { processes }\end{array}$} & Top down, mostly one way \\
\hline & & Unrealistic targets \\
\hline & & Bureaucracy \\
\hline & & Non-response to motivation letters \\
\hline & Supply chain processes & Long turn around and stock-outs \\
\hline & \multirow{2}{*}{$\begin{array}{l}\text { Employee Performance, } \\
\text { Motivation and } \\
\text { Development systems } \\
\end{array}$} & Waste of time \\
\hline & & Does not reward performance \\
\hline & \multirow{3}{*}{$\begin{array}{l}\text { Interactions: Supervision } \\
\text { systems }\end{array}$} & Policing supervision \\
\hline & & Erratic visits to facilities \\
\hline & & $\begin{array}{l}\text { Lack of power and ability to help facilities solve } \\
\text { problems }\end{array}$ \\
\hline \multirow[t]{9}{*}{ Tertiary factors } & \multirow[t]{4}{*}{ Actor perception } & High patient expectations \\
\hline & & Patient attitudes \\
\hline & & Staff attitudes \\
\hline & & Patients demanding care \\
\hline & \multirow[t]{5}{*}{ Actor responses } & Policing supervision (PHC supervisors) \\
\hline & & Buckpassing \\
\hline & & Non-responsive leadership \\
\hline & & Audit driven compliance with NCS \\
\hline & & Ideal reporting \\
\hline \multirow[t]{3}{*}{ Extraneous factors } & \multirow{3}{*}{$\begin{array}{l}\text { National vocational } \\
\text { training programmes }\end{array}$} & Shortage of plumbers and artisans \\
\hline & & Delayed repairs of brocken toilets and taps etc. \\
\hline & & Delayed repairs and maintenance \\
\hline
\end{tabular}




\begin{tabular}{lll}
\hline Theme & Category & Unit meaning \\
\hline Systems thinking & $\begin{array}{l}\text { Lack of planning ahead } \\
\text { and seeing the bigger } \\
\text { picture }\end{array}$ & Transition states not planned for \\
& & $\begin{array}{l}\text { Interconnectednesses not seen } \\
\text { Epidemiological transitions not planned for }\end{array}$ \\
\hline
\end{tabular}

PHC - primary healthcare, NCS - National Core Standards

structs (information, motivation, power, resources, interactions, context) not only indivdually but aslo jointly affected motivation.

\section{ONSLAUGHT ON MOTIVATION}

Staff motivation was revealed to be affected by so many interconnected factors. Lack of power and resources affected motivation, lack of information affected motivation and interactions too affected motivation. This effect on motivation is critical to point out since a policy can be good, resources may be available but if the implementing actors are not motivated, implementation will be affected. ${ }^{38}$ Dissatisfied clinical staff ${ }^{43}$ and burnout were revealed as recurring problems among nurses in South Africa. ${ }^{7,44}$ Involving the actors in policy planning, ensuring resource availability, granting them power and providing supportive supervision are all effective approaches that will not only improve policy implementation but also the motivation of the implementing actors. Our findings also demonstrated interconnectedness and relationships between primary, secondary, tertiary and extraneous factors, making systems thinking, a cross cutting and universal factor essential for successful policy implementation. A fault in one part of the system eg, lack of power inevitably affects the other parts for example resource mobilization and eventually the goal- quality health care services to all South Africans without financial impoverishment. ${ }^{5}$

\section{LACK OF POWER AND INTERCONNECTIONS}

Lack of power was revealed as affecting policy implementation at both district and facility levels. ${ }^{24}$ Lack of power in the district health system (DHS) was revealed as not only affecting services but was also linked to motivation, policing supervision, resources, infrastructure and all the other factors identified. Lack of resources can be viewed as lack of leadership. ${ }^{45}$ According to Ellokor and Gilson, it is local level managers (district, sub-district, programme and facility managers who must provide hands on leadership in strengthening the health system ${ }^{6}$ and to do that they need power. Chief executive officers (CEOs) need to receive appropriate delegations ${ }^{46}$ for them to function effectively. According to the world bank, decentralization can reduce administrative bottlenecks in decision making, increase efficiency of government and its responsiveness to local needs, enhance accoutability of public institutions, improve service delivery and allow greater representation and participation of diverse groups in decision making. ${ }^{27}$

\section{NO CONSULTATION-TOP DOWN DIRECTIVES}

Staff from facility up to district level, revealed that they were not consulted or involved in policy development. Such top down directives affect policy implementation (TommBonde et al., 2013). Top down directives have been proven to increase resistance. ${ }^{11,47,48}$ We did not encounter this phenomenon in our research. This could be due to the fact that UHC policies were hailed as novel, new at the time and were generally viewed by the international community ${ }^{1}$ health system actors and communities in South Africa as a positive development and right thing to do. ${ }^{5,48}$ In future, involving the implementing actors on the ground in policy development could go a long way in reducing policypractice gap. The facility actors are keen to be involved in policy development. They argue that context matters, that every facility is different, hence they understand the reality on the ground better than superiors at head office. Their involvement could lead to facility priorities being resolved faster and effectively, facilitating policy implementation. Nurses are demotivated by the way policies are being implemented. ${ }^{44}$ Involving implementing actors breeds a culture of innovation and makes it easier to pave the way for internal change. ${ }^{47}$

\section{DIFFERENT ACTOR PERCEPTIONS OF POWER}

Of interest were the different perceptions provincial, district, and facility actors had on power. Insufficient delegation of authority has been reported elsewhere. ${ }^{7}$ The District actors complained of lacking decision making authority and financial delegations ${ }^{27}$ while the provincial actors believed the district had sufficient power. In line with our findings, Gustaaf et al reported that district and hospital management lack mandates to carry out functions effectively ${ }^{43}$ including inadequate budget spending. ${ }^{27}$ Devolved decision making to teams on the ground contributes to successful implementation. ${ }^{45}$ Addressing DHS is of utmost importance if UHC is to become a reality. ${ }^{27,43,49}$ A DHS with power could also plan and allocate resources according to contextual needs, as the current conditional grants not only came late but are also attached with conditions making it difficult to deal decisively with priorities. The government still needs to invest significantly in strengthening PHC. 50

\section{THEME 2: SECONDARY FACTORS: A LACK OF EFFICIENT PROCESSES OR SYSTEMS}

Our findings also revealed that secondary factors, referring to shortcomings in processes or systems in the form of supervision support systems, 38 bureaucracy, employee man- 
agement and development system (EPMDS), ${ }^{38}$ lack of systems that take changing epidemiological profiles ${ }^{10,37}$ into account, disconnect between those who award contracts and those held accountable for service and transition states that are not planned for, were all contributing to policypractice discrepancies. Policy attention is requierd in terms of accountability. ${ }^{40}$ In support of our findings, weaknesses in support systems, logistics systems, , health information systems, coordination and referral systems have been reported elsewhere as affecting policy implementation. ${ }^{11,12,38}$ Capacity to implement is described as the target individuals, organizations and systems capacity to carry out policy objectives. ${ }^{51}$ The reason for South Africas deteriorating health outcomes lies in flaws in institutional design. ${ }^{43}$ All actors agreed that supply chain management (SCM) processes are affecting implementation. At the same time, all levels revealed how difficult an issue it is to resolve. A sense of urgency is needed in this regard as unresolved challenges continue to erode on staff motivation. ${ }^{52} \mathrm{Bu}$ reuacracy was also pointed at. All actors alluded to bureacracy as stalling policy implementation. They all professed lack of power to change what needed changing. These processes, supply chain and human factors (people in the system) were once again revealed as interconnected. Homogenous approaches to hospital processes and systems are needed. ${ }^{40}$ Our findings concur with Weaver ${ }^{39}$ who revealed that bureaucracy contains a variety of program operators namely; Saints-bureaucrats who are doing the best that they can under difficult working conditions. Many actors fell under this category. Shirkers are described as bureaucrats who avoid doing work whenever possible. Some actors at province pointed that many managers at district level fell in that category. Subverters are bureaucrats who substitute their own objectives for those of the principal or outcomes measured. Provincial actors and subdistrict actors felt there might have been some of these in the system and associated that with the Supply Chain Management. Shackled bureaucrats are those who have good intentions but are constrained by rules and red tape from being innovative to meet client individual needs. Many actors at district, subdistrict, and facility level expressed being in this group. Some came up with initiatives only to die, due to lack of support from above. Rent seekers are bureaucrats who use their position for personal gain. ${ }^{39}$ Actors suspected there could be some of these, due to the reluctance of some actors to deal decisively with systemic issues including supply chain. How many if at all of these actors are in the system is not clear. Weaver concludes that these program operators co-exist in a health system. 39

\section{INTERACTIONS: PHC SUPERVISION}

Lack of supportive supervision was a major complaint with many saying, You have told me what, now tell me how. 45 Lack of clear policies guiding all levels of the health system related to program implementation increase policy-practice gap. ${ }^{38}$ The emphasis of CIT lies on the social interactions and how they influence policy implementation processes. Communication was reported to be one-sided that is top to bottom. When the reasons and need for change are poorly communicated, actors feel frustrated and deflated. ${ }^{53}$ When facility actors need something urgent, they are told by their superiors to write motivational letters, which according to them, are not responded to, let alone acknowledged. Hierachy is the antithetical to dialogue. ${ }^{32}$ Performance is personal before it becomes organizational. Since people do not work in a vacuum, improved performance requires productive relationships with bosses, ${ }^{47}$ clients and community. Complex systems require effective interactions among staff, supervisors and clients to reach goals. ${ }^{54}$ The current employee management and development system (EPMDS) was cited by all as useless and a waste of time, calling for innovative ways of managing performance and motivating staff.

\section{THEME 3: TERTIARY FACTORS - A CALCULATED HUMAN RESPONSE TO THE LACK OF PRIMARY, EXTRANEOUS, SECONDARY OR ALL THESE FACTORS AS A COPING MECHANISM}

Our research revealed what we termed as tertiary factors. These are human factors and responses to either lack of primary, secondary, tertiary, extraneous and or all of these factors. These human factors took different forms (different perception of issues like power, ideal reporting, buckpassing, policing supervison, non-responsive leadership and audit driven compliance). Buckpassing has been reported elsewhere. ${ }^{55}$ These human responses are bringing about unintended consequences. Unintended consequences have been reported elsewhere in implementation. ${ }^{11}$ Ideal reporting and audit driven compliance with standards, as a human response to lack of primary factors or secondary factor is a novel finding of this research.

\section{HUMAN FACTOR, PERCEPTION AND BUREAUCRACY PROGRAM OPERATORS}

People and the role people play in policy implementation, particularly communication, was demonstrated by the level of understanding and motivation of those actors that attended the Ministers road shows. He seemed to have communicated clearly and motivated those that attended. Its not clear if its power, charisma or both but his shows seemed to have had an impact on policy understanding. Those who attended his shows not only revealed a better understanding of NHI but a degree of optimism as well. Actors that did not attend the Ministers road shows expressed little understanding of NHI and its policies. Inadequate information leads to misunderstandings and lack of direction. ${ }^{47}$ In line with our findings, role ambiguity in policy implementation was reported as affecting policy implementation. ${ }^{24}$ The role of individual perception was revealed to play a major role in policy implemention. Our findings concur with Anderson who revealed that many differing assessments to a given situation exist. ${ }^{47}$ Different actors perceived things and issues differently. Perceptions of issues tended to be different at each level of the health system from provincial, district to facility level. The facility actors expressed for example a shortage of equipment, while the district and provincial actors viewed equipment as sufficient. These different actor perceptions of issues included among others power the district had, human resource situation, and understanding of NHI. Concuring with our find- 
ings, Interpretation issues were documented elsewhere, where key elements of policies were left indeterminate leading to substantial lost time and energy as implementers argue about ambiguous objectives and mandates. ${ }^{39,56}$ of concern, different actors at different levels had different perceptions of the situation on the ground and how to solve them. ${ }^{57}$ In-order to meet financial and other targets, managers and clinicians have to be encouraged to understand one anothers viewpoints and experiences. ${ }^{49,52}$

\section{IDEAL REPORTING}

Facility actors expressed how they adapt policy to suit the needs on the ground. This finding is in line with research elsewhere. Policies often go some tailoring or adaptations when implemented in different contexts. ${ }^{14}$ Of interest is the ideal reporting which actors said they did in response to policing supervision. If they send a report to their superiors without using the expected format, the report is sent back and they are told to do it over again. They discovered that if they reported according to what is expected, they are left in peace. Weaver et al found out that actors use their discretion to make their jobs easier e.g managing overwhelming work loads or difficult clients rather than advance policy eg, physicians may provide a higher volume of services to benefit economically. 39

\section{ASSESSMENT DRIVEN COMPLIANCE WITH NATIONAL CORE STANDARDS (NCS)}

Actors described how unresolved challenges, chronic resource shortages and policing supervison led to assessment driven compliance with NCS. This interesting phenomenon was common in phase one when facility managers went around borrowing equipment, ${ }^{24}$ drugs and policy documents in oder to pass the assessment, only to bring the equipment back post assessment. This creates a false impression of progress towards NCS when in actual fact the day to day running of facilities remains unchanged. Adversarial relations between reporting entity and the organization can drive non-compliance. ${ }^{45}$ According to the NHI whitepaper, the piloting phase one (from 2011/2012 to 2017) was supposed to achieve strengthening of the service delivery platform and overall improvement of quality in the public sector. ${ }^{5}$ Are we there yet?

The Office of Health Standards Compliance (OHSC) responsible for assessing National Core Standards conducted inspections in 1427 public hospitals and clinics over a fouryear period up to 31 March 2016 . Only 89 (6\%) of the facilities met the pass mark of $70 \%{ }^{27,40}$ The actual figure might even be lower in light of compliance driven assessments. We acknowledge that assessments have their place in ensuring quality, but doing so at this stage seems to be generating unintended consequences, due to the multiple unresolved challenges facilities are facing. Instead of NCS audits, we recommend that the office of NCS standards carries on with higher level support visists to facilities and so rather than assess, engage with facilities and assist them in overcoming the multltiple unresolved challeges they have, so as to meet standards and reach accreditation. It is also important to note that service readiness and availability do vary over- time, demanding close attention. ${ }^{27}$ A facility that is compliant today might not be compliant tomorrow if for example a driven operational manager resigns or of equipment break and is not replaced.

\section{PATIENT STAFF ATTITUDES}

Facility actors revealed how patient-staff attitudes are often misconstrued as as rude staff illtreating patients, but that the mistrust is being fuelled by high patient expectations at the backdrop of resource shortages on the ground. This is a phenomenon worth exploring as it is affecting staff motivation. Resource provision is beyond facility actors and supervisors blame them when patients wait for too long and they also get blamed them when a facility has no oxygen, issues well beyond their mandate. Facility actors termed this policing supervision. In line with our findings, blame culture in this context has been reported by others. ${ }^{24,44}$ There is in each of us a propensity to blame soemone or something else when things go wrong. ${ }^{32}$ When mistakes are viewed as bad things and held against actors instead of being used as learning and opportunities for reflection, such organizations foster a culture of transferring responsibility of one`s mistakes to others, hence never become learning organizations. ${ }^{58}$ Nurses took to the street expressing that they are being attacked by patients, relatives and communities, accusing them of being lazy, incompetent or negligent and yet it's because they are short staffed. ${ }^{41}$ Performance is personal and is affected by relationships between clients and community. ${ }^{47}$ Lack of progress in establishing structures for community participation has been reported. Though hospital boards and clinic commttees have been established in some facilities, its not clear how these bodies facilitate meaningful community participation. ${ }^{27}$

\section{MANAGING STAKEHOLDER EXPECTATIONS IS KEY IN POLICY IMPLEMENTATION}

Management of expectations of key stakeholders in the health system, particularly patients and communities, is called for. The whole society should have a responsibilty to account. ${ }^{50}$ These issues need to be visited and addressed if policy implemetation is to succeed and the current patientstaff attitudes are to be overcome.

\section{THEME 4: EXTRANEOUS FACTORS: FACTORS BEYOND THE HEALTH SYSTEM}

Extraneous factors are defined as factors of an external origin beyond the health sector. Our findings revealed how national vocational training regulations were contributing to supply chain woes, in the form of lack of artisans. These are factors beyond the ministry of health, ${ }^{11}$ but are contributing to policy-practice gaps. We recommend taking issues beyond the health sector like brain drain, economic situation etc. into account when planning and implementing policies including intersectoral collaboration and health in all polices approach ${ }^{59}$ to reduce this gap. 


\section{THEME 5: LACK OF STYSEMS THINKING}

Systems thinking is a conceptual framework, a body of knowledge and tools that have been developed to make patterns of events clearer and help one see how to change them effectively. It's a way of seeing wholes rather than parts, seeing interelationships rather than things. ${ }^{32}$ Our findings have revealed relationships and interconnectedness among primary, secondary, tertiary and extraneous factors; hence we think it deserves to be mentioned separately as a standalone factor contributing to the policy-practice gap. Seeing major interelationships underlying a problem leads to new insights of what might be done. ${ }^{32}$ Actors pointed at the lack of systems thinking in different forms including computer procurement without security and training, lack of planning for transition states, lack of strategic planning skills and focus on short term planning. These findings are supported by research done elsewhere. ${ }^{43}$ Officials and staff of central health ministries often struggle with managing information over load and competing priorities ${ }^{38}$ making it difficult for them to see wholes. ${ }^{32}$ A lack of systems thinking affects primary, secondary, teriary and extraneous factors making systems thinking a universal factor needed to be taken into account during policy planning and implementation. Factors in one group eg, primary have their own relationships and interconnections within that category eg, lack of information affects motivation. Furthermore, factors in the primary group eg, motivation are also affected by secondary factors eg, supply chain processes and vice versa. Primary or secondary factors themselves can futher be affected by extraneous factors like vocational training and by tertiary factors like non-response from leaders. The interconnectedness of factors is worthy reckoning with as these add complexity in implementation, further widening the policy practice-gap.

\section{TRANSITION STATES}

Policy implementation is a process and does not happen overnight. In line with systems thinking, actors revealed how transition states are not planned for. Transition shifts power and resources, creates additional work and may bring about unwelcome shifts in organizational priorities. All of these factors may create resentment and negativity toward the transition process. ${ }^{60}$ Poorly executed transitions risk reversing health achievements, negatively affecting services and outcomes for the population. ${ }^{60}$ Even in instances where human, technological and other resources required for successful implementation are present, it takes time to put all needed systems in place and to make them work effectively. ${ }^{39}$ Accountability is needed for successful transition $^{60}$ hence we recommend transition authorities during new policy roll-out. Such an authority could serve as the body or person to contact in case there is a policy-context discrepancy and enhance policy implementation.

The bottom line in systems thinking is leverage-seeing where action and changes in structures can lead to significant enduring improvements-the principle of economy of means. The best results do not come from large scale efforts but small focused actions. ${ }^{32}$ Despite the existence of unkown unkowns in policy, many implementation problems recurr across many programs and are quite predictable at least in their occurrence if not in their intensity. ${ }^{39}$ To minimise unanticipated consequences, policy makers need to understand health care as a complex system and apply principles of complexity science, ${ }^{54}$ one of which is sytems thinking to achieve goals. Systems thinking helps deepen our understanding of complexity and the practical dynamics of policy implementation. ${ }^{61}$ Constantly changing guidelines were pointed at by some actors, raising the risk of change fatigue. ${ }^{53}$ Of utmost importance is the need for $d y-$ namic leadership that can drive subordinates to embrace challenges of constant change, in a dynamic world of continual evolution, the health system is. ${ }^{53}$

\section{STUDY LIMITATIONS AND STRENGTHS}

Implementation research entails the challenge of operationalizing and measuring implementation constructs because sufficiently valid measures often do not exist. Secondly, implementation research is just one component needed in a strong evaluation. Used alone, it will not establish causality or the efficacy of an innovation. ${ }^{62}$ Qualitative studies are context specific, findings though transferable may differ from studies done in different contexts. ${ }^{63}$ Finally, our study did not cover other national policies being implemented, but focused only on those reforms aimed at achieving Universal Health Coverage.

Very few systems are set up for the purpose of documenting and tracking policy implementation and monitoring in low and middle-income countries (LMIC). This was one of the first systems in SA to track UHC policy implementation, generating real time evidence on why policies fail. Furthermore, few studies have focussed explicitly on developing a qualitatitive understanding of the experiences of those at all levels of the health system province, district, subdistrict and facility, comparing and contrasting their implementation experience of the same policies (UHC). In this paper, we managed to reveal the challenges actors (policy makers and policy implementers) face during policy implementation, actions they undertake to cope with challenges and how these actions further widen the policy-practice gap.

Methodologically, theory of change facilitated actors to reflect on their expectations, roles and experiences of UHC policy implementation over a period of time, enhancing not only depth, breath, credibility but also richness of our results. Triangulation and comparison of policy implementation experiences across the different levels of the health system from province, district, subdistrict to facility level, provides a wholistic picture of what is going on in UHC policy implementation in South Africa.

\section{CONCLUSIONS}

Dedicated and committed political will is requred over the long term for UHC to be achieved. ${ }^{27}$ Existing experience of health policy implementation has demonstrated that new policies have generated unexpected and sometimes negative outcomes. ${ }^{64,65}$ Policies, once adopted, are not always implemented as envisioned and do not necessarily achieve intended results. ${ }^{13}$ The South African public sector is experiencing a management crisis. ${ }^{46}$ Lack of power, financial delegetions at district and facility level, coupled with lack of 
accountability, affect policy implementation. According to a provincial actor, there is an additional challenge.

"The main challenge is that this NHI is a new issue. We are all at a learning stage. National down to district level." - provincial actor round 1.

This challenge sums it all. Progress towards UHC have been made ${ }^{27}$ and initiatives like bringing doctors into the clinics ${ }^{66}$ and central chronic medicine dispensing have been met with success. ${ }^{37}$ The focus of this paper is on understanding how policy-practice gaps come about, ${ }^{32}$ hence successful policy outcomes were not dwelt upon.

A health system is a complex adaptive system making health care challenges complex and intractable (wicked problems) since they involve many actors from different levels of the organization and interconnectedness that introduce added layers of complexity. In implementation, focus is usually put on ensuring that primary factors, information, motivation, power and resources are in place. Our research revealed that paying attention to secondary, tertiary and extraneous factors individually and jointly is equally important in reducing policy-practice discrepancies in UHC policy implementation. Worthy noting are the human responses of actors in the system (tertiary factors) further widening that gap. We acknowledge that there are no easy solutions to wicked problems as every complex problem is unique. ${ }^{57}$ We are also cognisant of the fact that policy implementation is seldom linear ${ }^{42,48}$ and requires a lengthy period of implementation. ${ }^{57}$ South Africa needs to be applauded for adopting UHC. Addressing the challenges identified in our research, utilizing a systems approach ${ }^{32,57}$ could go a long way in making UHC a reality in South Africa.

\section{ACKNOWLEDGEMENTS}

We thank members of the UNITAS project team including Professor Lucy Gilson, Professor Jane Goudge, Dr Bronwyn Harris, Kafayat Oboirien, Maylene Shung King and Mr Ermin Erasmus. Special thanks to all Department of Health staff at provincial, district and sub-district levels, as well as PHC managers and PHC staff who took part in the study.

\section{ETHICS}

The study was conducted in full compliance with the principles of "Declaration of Helsinki" (as amended in Tokyo, Venice, Hongkong and South Africa and the laws and regulations of South Africa. UNITAS obtained Full Ethical approval for the study granted by the University of KwaZuluNatal Biomedical Research Ethics Committee; REF BE197/ 13. Gatekeepers permission was granted by the KZN Provincial Health Department; REF HRM4/2. A support letter was also obtained from the District Manager. In addition, informed written consent was obtained from actors who took part in the study.

\section{AVAILABILITY OF DATA AND MATERIAL}

Data and material from this study cannot be provided publicly due to our ethical obligations to protect anonymity of participants. As stipulated in the participants "informed consent form," data access is limited to members of UNITAS research team. Data cannot be shared due to this restriction. For further information related to data, please contact the corresponding author.

\section{FUNDING}

This research was funded through the European Commission's Seventh Framework Programme (FP7-CP-FP-SICA, grant agreement number 261349).

\section{COMPETING INTERESTS}

The authors completed the Unified Competing Interest form at http://www.icmje.org/coi disclosure.pdf (available upon request from the corresponding author), and declare no conflicts of interest.

\section{CORRESPONDENCE TO:}

Janet Michel

Bahnhofstrasse 75, Roggwil 4914

Switzerland

janetmichel71@gmail.com 


\section{REFERENCES}

1. Bump JB. The Long Road to Universal Health Coverage: Historical Analysis of Early Decisions in Germany, the United Kingdom, and the United States. Health Syst Reform. 2015;1(1):28-38. doi:10.4161/2328 $\underline{8604.2014 .991211}$

2. Wikipedia.org. List of countries with universal health care. Accessed July 23, 2019. https://en.wikipe dia.org/wiki/List_of_countries_with_universal_healt h_care

3. Evans DB, Hsu J, Boerma T. Universal health coverage and universal access. Bull World Health Organ. 2013;91(8):546-546A. doi:10.2471/blt.13.1254 $\underline{50}$

4. McIntyre D, Doherty J, Ataguba J. Universal Health Coverage Assessment South Africa. Global Network for Health Equity; 2014.

5. National Department of Health. South Africa. National Health Insurance for South Africa White Paper. Accessed July 23, 2019. http://www.health.go v.za/index.php/nhi

6. Ellokor S, Gilson L. The DIAHLS project. In: District Innovation and Action Learning for Health System Development in 2nd HSR Symposium. 2012.

7. Harrison D. An Overview of Health and Health care in South Africa 1994 - 2010: Priorities, Progress and Prospects for New Gains 40. Published 2010. Accessed July 23, 2019. http://ftp.bhfglobal.com/files/bhf/overv iew1994-2010.pdf

8. Dookie S, Singh S. Primary health services at district level in South Africa: a critique of the primary health care approach. BMC Fam Pract. 2012;13(1):67. doi:10.1186/1471-2296-13-67

9. Mohlakoana N. Energy Policy A Dynamic Actor Interaction Nthabiseng Mohlakoana Implementing the South African Free Basic Alternative Energy Policy A Dynamic Actor Interaction. Accessed July 23, 2019. https://research.utwente.nl/en/persons/nthabis eng-mohlakoana/publications/?type=\%2Fdk\%2Fatir a\%2Fpure\%2Fresearchoutput\%2Fresearchoutputtype s\%2Fthesis\%2Fdoc1

10. Leader.co.za. 9 major problems facing South Africa - and how to fix them. Accessed July 23, 2019. $\underline{\mathrm{h}}$ ttp://www.leader.co.za/article.aspx? $\mathrm{s}=1 \& \mathrm{f}=1 \& \mathrm{a}=2893$
11. Burke K, Morris K, McGarrigle L. An introductory guide to implementation: terms, concepts and frameworks. Centre for Effective Services, Dublin. Published 2012. Accessed July 23, 2019. https://www.1 enus.ie/handle/10147/306846

12. Hunter DJ, Killoran A, NHS Health Development Agency. Tackling Health Inequalities: Turning Policy into Practice? NHS Health Development Agency; 2004.

13. Bhuyan A, Jorgensen A, Sharma S. Taking the Pulse of Policy: The Policy Implementation Assessment Tool. Accessed July 23, 2019. http://ww w.healthpolicyplus.com/archive/ns/pubs/hpi/115 5 1_PIAT_Paper_Taking the Pulse_of_Policy_acc.pdf

14. Moore GF, Audrey S, Barker M, et al. Process evaluation of complex interventions: Medical Research Council guidance. BMJ. 2015;350:h1258. do i:10.1136/bmi.h1258

15. Health Policy Project, Capacity development. Implementation Barriers Resource Guide. https://ww w.healthpolicyproject.com/pubs/272 Implementation BarriersResourceGuide.pdf

16. Stone D. Learning lessons, policy transfer and the international diffusion of policy ideas. Cent. Study Glob. Reg. Work. Pap. Published 2001. Accessed July 23, 2019. http://wrap.warwick.ac.uk/2056/1/WRAP St one_wp6901.pdf

17. Hans B. Implementing Sustainable Development: How to Know What Works, Where, When and How. In: Governance for Sustainable Development: The Challenge of Adapting Form of Function. Edward Elgar; 2004:284-318. Accessed July 23, 2019. https://researc h.utwente.nl/en/publications/implementing-sustaina ble-development-how-to-know-what-works-where

18. Hongoro C, Rutebemberwa E, Twalo T, et al. Analysis of selected policies towards universal health coverage in Uganda: the policy implementation barometer protocol. Arch Public Health. 2018;76(1):12. doi:10.1186/s13690-018-0258-4

19. Mohlakoana N. Energy Policy A Dynamic Actor Interaction Nthabiseng Mohlakoana Implementing the South African Free Basic Alternative Energy Policy A Dynamic Actor Interaction. University of Twente. Accessed July 23, 2019. https://research.utwe nte.nl/en/persons/nthabiseng-mohlakoana/publicatio ns/?type=\%2Fdk\%2Fatira\%2Fpure\%2Fresearchoutpu t\%2Fresearchoutputtypes\%2Fthesis\%2Fdoc1 
20. O'Toole LJ. The Theory-Practice Issue in Policy Implementation Research. Public Adm. 2004;82(2):309-329. doi:10.1111/j.0033-3298.2004.00 396.X

21. Spratt K. Policy Implementation Barriers Analysis: Conceptual Framework and Pilot Test in Three Countries. Accessed July 23, 2019. http://www.health policyinitiative.com/Publications/Documents/99 81 1_PIBA_FINAL 120709 acc.pdf

22. Signe L. Policy Implementation - A synthesis of the Study of Policy Implementation and the Causes of Policy Failure. Accessed July 23, 2019. https://www.po licycenter.ma/sites/default/files/OCPPC-PP1703.pdf

23. Bressers JTA. From public administration to policy networks: Contextual interaction analysis. In: Rediscovering Public Law and Public Administration in Comparative Policy Analysis: A Tribute to Peter Knoepfel. Presses polytechniques et universitaires romandes; 2009:123-142.

24. Oboirien K, Harris B, Goudge J, Eyles J. Implementation of district-based clinical specialist teams in South Africa: Analysing a new role in a transforming system. BMC Health Serv Res. 2018;18(1):600. doi:10.1186/s12913-018-3377-2

25. de Boer C, Bressers H. Complex and Dynamic Implementation Processes. Accessed July 23, 2019. ht tps://ris.utwente.nl/ws/portalfiles/portal/12836687/C omplex_and_Dynamic_Implementation_Processes.pdf

26. Weiss $\mathrm{CH}$. Nothing as Practical as Good Theory: Exploring Theory-Based Evaluation for Comprehensive Community Initiatives for Children and Families. Accessed July 23, 2019. https://pdfs.sem anticscholar.org/ff5a/3eea8d1d4e07a768ded6b426b42 5efde8f7c.pdf? ga =2.104086592.1175507431.1563887 $\underline{831-357266355.1563887831}$

27. Fusheini A, Eyles J. Achieving universal health coverage in South Africa through a district health system approach: conflicting ideologies of health care provision. BMC Health Serv Res. 2016;16(1):558. doi:1 $\underline{0.1186 / \mathrm{s} 12913-016-1797-4}$

28. Press Academia. Definition of Case Study. Accessed July 23, 2019. https://www.pressacademia.or g/definition-of-case-study

29. Huge applause for the KZN department of health as patients collect chronic medication closer to home and save on traveling costs. Accessed July 23, 2019. ht tp://www.kznhealth.gov.za/mediarelease/2016/Hugeapplause-for-the-kzn-department-of-health-a-\%20pa tients.htm
30. Forero R, Nahidi S, De Costa J, et al. Application of four-dimension criteria to assess rigour of qualitative research in emergency medicine. $B M C$ Health Serv Res. 2018;18(1):120. doi:10.1186/s12913-0 18-2915-2

31. Saunders B, Sim J, Kingstone T, et al. Saturation in qualitative research: exploring its conceptualization and operationalization. Qual Quant.

2018;52(4):1893-1907. doi:10.1007/s11135-017-057 $\underline{4-8}$

32. Senge PM. The Fifth Discipline: The Art and Practice of the Learning Organization. Random House Business Books; 1999.

33. Matland RE. Synthesizing the implementation literature: The ambiguity-conflict model of policy implementation. J Public Adm Res Theory. 1995;5:145-174.

34. Bowen S, Zwi AB. Pathways to "evidenceinformed" policy and practice: A framework for action. PLoS Med. 2005;2(7):e166. doi:10.1371/journa l.pmed.0020166

35. Power definition and meaning. Collins English Dictionary. Accessed July 23, 2019. https://www.collin sdictionary.com/dictionary/english/power

36. National Department of Health. South Africa. Status of NHI Pilot Districts. 12-Month Progress Report. NHI pilot district assessment final; 2015. Accessed July 23, 2019. http://www.health.gov.za/index.php/20 14-03-17-09-09-38/reports/category/176-reports-201 5

37. Kettledas R. Central Chronic Medicine Dispensing And Distribution Programme. Accessed July 23, 2019. https://za.usembassy.gov/wp-content/uploads/sites/1 9/2016/06/Central-Chronic-Medicine-Dispensing-an d-Distribution-Programme Ricardo-Kettledas.pdf

38. Health policy project. The Policy Dimensions of Scaling Up Health Initiatives. Accessed July 23, 2019. https://www.healthpolicyproject.com/pubs/83_Scaleu pPolicyJuly.pdf

39. Weaver RK. But Will It Work?: Implementation Analysis to Improve Government Performance. Accessed July 23, 2019. https://www.brookings.edu/w p-content/uploads/2016/06/02_implementation_analy sis weaver.pdf

40. Health Systems Trust. South African Health Review (SAHR 2017). Published 2017. Accessed July 23, 2019. https://www.hst.org.za/publications/Sout h\%20African\%20Health\%20Reviews/Foreword,\%20Ta ble\%20of\%20Contents\%20and\%20Acknowledgement s.pdf 
41. News24. "We are not slaves" - KZN nurses call for health MEC to be axed. Accessed July 23, 2019. http s://www.news24.com/SouthAfrica/News/we-are-not-s laves-kzn-nurses-call-for-health-mec-to-be-axed-20 180718

42. Peters DH, Adam T, Agyepong AO.

Implementation research: what it is and how to do it. BMJ. 2013;347:f6753.

43. Wolvaardt G. How to fix the district health care system: what District Managers told us in 2013 about the obstacles and challenges they face. Accessed July 23, 2019. https://sahivsoc.org/Files/Fri Gustaaf_Wolv aardt\%20How\%20to\%20fix\%20our\%20distric\%20heal th\%20system.pdf

44. Khunou SH, Davhana-Maselesele M. Level of job satisfaction amongst nurses in the North-West Province, South Africa: Post occupational specific dispensation. Curationis. 2016;39(1):1438. doi:10.410 2/curationis.v39i1.1438

45. Tomm-Bonde L, Schreiber RS, Allan DE, MacDonald M, Pauly B, Hancock T. Fading vision: knowledge translation in the implementation of a public health policy intervention. Implementation Sci. 2013;8(1):59. doi:10.1186/1748-5908-8-59

46. Strengthening clinical leadership in hospitals. A review of the international and South African literature. Accessed July 23, 2019. https://www.wits.a c.za/media/migration/files/cs-38933-fix/migratedpdf/ pdfs5/Strengthening\%20clinical\%20leadership\%20i n\%20hospitalsVers2.pdfpdf

47. Anderson N. Top-Down or Bottom-Up Approaches to Successful Change. Accessed July 23, 2019. http://w ww.tbointl.com/blog/top-down-or-bottom-up-approa ches-to-successful-change

48. Béland D, Ridde V. Ideas and Policy implementation: Understanding the resistance against free health care in Africa. Glob Health Gov. 2016;3:15.

49. Doherty J, Gilson L, Shung-King M. Achievements and challenges in developing health leadership in South Africa: the experience of the Oliver Tambo Fellowship Programme 2008-2014. Health Policy Plan. 2018;33(suppl_2):ii50-ii64. doi:10.1093/heapol/czx15 $\underline{5}$

50. Tangcharoensathien V, Mills A, Das MB, Patcharanarumol W, Buntan M, Johns J. Addressing the health of vulnerable populations: social inclusion and universal health coverage. J Glob Health. 2018;8(2). doi:10.7189/jogh.08.020304
51. Dodson EA, Brownson RC, Weiss SM. Dissemination and Implementation Research in Health. Translating Science into Practice. Oxford University Press; 2012.

52. World Health Organization. Leading health system transformation to the next level. Expert meeting Durham, United Kingdom, 12-13 July 2017. Accessed July 23, 2019. http://www.euro.who.int/ da ta/assets/pdf_file/0008/369971/Leading-health-syste ms-transformation-to-the-next-level-report-eng.pdf

53. Ditch 'Change Fatigue' and Embrace Continual Evolution. Cent. Creat. Leadersh. Published 2017. Accessed July 23, 2019. https://www.ccl.org/blog/chan ge-fatigue-continual-evolution/

54. Lipsitz LA. Understanding healthcare as a complex system. JAMA. 2012;308(3):243-244. doi:1 0.1001/jama.2012.7551

55. Dörrenbächer N, Mastenbroek E. Passing the buck? Analyzing the delegation of discretion after transposition of European Union law. Regul Gov. 2017;13(1):70-85. doi:10.1111/rego.12153

56. Bellush J. The politics of policy implementation. By Robert Nakamura and Frank Smallwood. St. Martin's Press, 175 Fifth Avenue, New York 10010, 1980. xii, 201 pp. Nat Civic Rev. 1981;70(10):553-556. doi:10.1002/ncr.4100701010

57. Strehlenert H. From policy to practice: exploring the implementation of a national policy for improving health and social care. Published 2017. Accessed July 23, 2019. https://openarchive.ki.se/xml ui/handle/10616/46019

58. Ackoff RL. Why few organizations adopt systems thinking. Syst Res Behav Sci. 2006;23(5):705-708. do $\mathrm{i}: 10.1002 /$ sres.791

59. World Health Organization. Health in all policies (HiAP). Framework for Country Action. Published 2014. Accessed July 23, 2019. https://www.who.int/he althpromotion/hiapframework.pdf

60. Bao J, Rodriguez DC, Paina L, Ozawa S, Bennett S. Monitoring and Evaluating the Transition of LargeScale Programs in Global Health. Glob Health Sci Pract. 2015;3(4):591-605. doi:10.9745/ghsp-d-15-002 $\underline{21}$

61. Adams-Jack U. Implementation gaps, policy change and health system transformation in the Western Cape Province, South Africa. Politeia. 2016;35(1):1-18. doi:10.25159/0256-8845/1518 
62. Using Implementation Research to Guide Adaptation, Implementation, and Dissemination of Patient-Centered Medical Home Models. Accessed July 23, 2019. https://pcmh.ahrq.gov/sites/default/file s/attachments/UsingImplementation_032513comp.pd f

63. Brugha R. Stakeholder analysis: a review. Health Policy Plan. 2000;15(3):239-246. doi:10.1093/heapol/1 $\underline{5.3 .239}$

64. Gutura P, Tanga PT. "Bargaining with Children”: Unintended Consequences of children's grants in rural South Africa. J Sociol Soc Anthropol. 2016;7(1):35-43. doi:10.1080/09766634.2016.1188570 $\underline{0}$
65. de Paoli M, Mills E, Grønningsæter A. The ARV roll out and the disability grant: a South African dilemma? J Int AIDS Soc. 2012;15(1):6. doi:10.1186/17 58-2652-15-6

66. Mureithi L, Burnett JM, Bertscher A, English R. Emergence of three general practitioner contractingin models in South Africa: a qualitative multi-case study. Int J Equity Health. 2018;17(1):107. doi:10.1186/ s12939-018-0830-0 